University of Miami Law School University of Miami School of Law Institutional Repository

2011

\title{
Controlling Sexually Violent Predators: Continued Incarceration at What Cost?
}

Tamara Rice Lave

University of Miami School of Law, tlave@law.miami.edu

Follow this and additional works at: https://repository.law.miami.edu/fac_articles

Part of the Criminal Law Commons, Criminal Procedure Commons, and the Law and Society Commons

\section{Recommended Citation}

Tamara Rice Lave, Controlling Sexually Violent Predators: Continued Incarceration at What Cost?, 13 New Crim. L. Rev. 213 (2011).

This Article is brought to you for free and open access by the Faculty and Deans at University of Miami School of Law Institutional Repository. It has been accepted for inclusion in Articles by an authorized administrator of University of Miami School of Law Institutional Repository. For more information, please contact library@law.miami.edu. 


\title{
CONTROLLING SEXUALLY VIOLENT PREDATORS: CONTINUED INCARCERATION AT WHAT COST?
}

\author{
Tamara Rice Lave*
}

Sexually violent predator (SVP) laws are inherently suspicious because they continue to incarcerate people not because of what they have done, but because of what they might do. I focus on three major criticisms of the laws. First, I use recent recidivism data to challenge the core motivation for the SVP laws_that sex offenders are monsters who cannot control themselves. Second, I situate the laws theoretically as examples of what Feeley and Simon call the "new penology." I argue that the SVP laws show the limited promise of the new penology-that we can use science to predict risk accurately-because the actuarial instruments used in SVP determinations make many mistakes. In making this argument, I focus particularly on the most commonly used such instrument, the Static-99. Finally, I argue that the Static-99 fails to meet the constitutional criteria laid out by the U.S. Supreme Court in Kansas $v$. Hendricks because it does not link an individual's mental illness to his dangerousness.

During the 1980s, three unconscionable crimes occurred in the State of Washington that changed the American legal landscape. In September 1988, Diane Ballasiotes was raped and murdered by a convicted felon whose chance for successful adjustment to the community had been deemed "quite

*Associate Professor, University of Miami School of Law; Ph.D., Jurisprudence and Social Policy, University of California, Berkeley; J.D., Stanford Law School; B.A. Haverford College.

This paper was presented at the Annual Meeting of the American Society of Criminology in 2005, with the title Controlling the Offender: Sex, Mental Illness, and the Static 99. I have benefitted from the comments of many people, but I would like to particularly thank Al Blumstein, Phil Cook, Greg LaBlanc, Santhi Leon, Rob MacCoun, Justin McCrary, John Monahan, Jonathan Simon, and Bob Weisberg. I would also like to thank Jim Lynch and

New Criminal Law Review, Vol. 14, Number 2, pps 213-280. ISSN 1933-4192, electronic ISSN 1933-4206. (C) 201 by the Regents of the University of California. All rights reserved. Please direct all requests for permission to photocopy or reproduce article content through the University of California Press's Rights and Permissions website, http://www. ucpressjournals.com/reprintInfo.asp. DOI: 10.1525/nclr.2011.14.2.213. 
poor" by a prison psychologist.' Three months later, a mentally retarded man who had been charged with four violent rapes broke into the apartment of a twenty-three-year-old woman, removed her light bulb, and waired. When the woman returned home, he slashed and raped her. ${ }^{2}$ Finally in May 1989, Earl Shriner-a mentally retarded parolee with a history of kidnapping, rape, and murder-dragged a seven-year-old boy into the woods. Shriner raped the boy, cut off his penis, and left him to die. ${ }^{3}$ Prison officials had known that Shriner was planning to torture children when he was released from prison, ${ }^{4}$ yet they were unable to prevent his release. ${ }^{5}$

The public was outraged. Thousands of letters to the governor flooded in, and public forums were held to address child sexual assault. ${ }^{6}$ In February 1990, nine months after Shriner's horrific crime, Washington responded to the mounting pressure by passing the Community Protection Act authorizing the indefinite commitment of individuals determined to be sexual violent predators after they had completed their maximum prison term. ${ }^{7}$ To commit someone under Washington's law, the state must prove that the accused (I) has at least one prior crime of sexual violence, and (2) currently suffers from a mental abnormality or personality disorder that makes him likely to engage in future predatory acts of sexual violence. ${ }^{8}$

Tom Zelenock for introducing me to the Bureau of Justice statistics at the 2006 ICPSR Summer Training Program in Quantitative Analysis of Crime and Criminal Justice. I am especially indebted to my dad, Lester Lave, and Frank Zimring for their invaluable suggestions. I would also like to thank the reviewers and editors at the New Criminal Law Review-particularly Cher Paul and Mark Penrose. Any mistakes, of course, are my own.

r. Column One, Locking up "Sexual Predators," A Public Outcry in Washington State Targeted Repeat Violent Sex Criminals, A New Preventative Law Would Keep them in Jail Indefinitely, Los Angeles Times, May ro, 1990, Home Edition at 2 (hereinafter Sexual Predators).

2. Id. at 3.

3. Id.

4. Id.

5. Officials tried to commit Shriner under Washington's Involuntary Treatment Act, but he had not committed a recent overt act, so he did not qualify. Roxanne Lieb, Vernon Quinsey \& Lucy Berliner, Sexual Predators and Social Policy, in Crime and Justice 66, 43-II4 (M. Tonry ed., 1998).

6. Sexual Predators, supra note I, at 4.

7. Michael G. Petrunik, Managing Unacceptable Risk: Sex Offenders, Community Response, and Social Policy in the United States and Canada, 46(4) Int'l J. Offender Therapy \& Comp. Criminology 483 at 492 (2002).

8. Wash. Rev. Code $\$ 71.09 .020$ (2008). 
Currently twenty states and the federal government have laws calling for the involuntary civil commitment of sexually violent predators. These include Arizona, California, Florida, Illinois, Iowa, Kansas, Massachusetts, Minnesota, Missouri, Nebraska, New Hampshire, New Jersey, New York, North Dakota, Pennsylvania, South Carolina, Texas, Virginia, Washington, and Wisconsin. By the summer of 2008 , over 3,45I individuals were confined nationwide pursuant to sexually violent predator laws. ${ }^{9}$ At least 262 more are being detained to determine whether they should be committed as an SVP. ${ }^{10}$ As of September 23, 2008, 606 sexually violent predators were committed in California alone. ${ }^{11}$

Implementing these laws demands enormous resources. ${ }^{12}$ When there were only sixteen SVP states, funding was estimated to be $\$ 275-300$ million per year. ${ }^{13}$ To meet these costs, some states have taken measures like reducing the number of probation officers and cutting funds to domestic violence and sexual violence prevention programs. ${ }^{14}$ Despite these costs,

9. On August 13, 2008, I wrote to each of the states that had passed sexually violent predator legislation and asked for data regarding commitments in their state. Specifically, I requested information on the number of commitments, the number in process of being committed, the number released, the types of offenses they had committed, and a breakdown by race, gender, and age. I received data from all of the states except Florida and Nebraska, and I received incomplete data from Massachusetts. For these three states I used data that was published in a New York Times article in 2007. Since that data was collected in 2006, and since the laws are still in effect, I am assuming that these states had more committed SVPs in 2008 than they did in 2006. Doubts Rise as States Hold Sex Offenders after Prison, The New York Times, Mar. 4, 2007, AI at AI8, http://www.nytimes.com/imagepages/2007/03/03/us/20070304_CIVIL_ GRAPHIC.html. Not all states use the terminology, "sexually violent predator." Other terms include, "sexually dangerous person," and "sexually violent person." Since the legislation is very similar, I have decided to use one term for the sake of simplicity: sexually violent predator or SVP.

ro. This includes 140 detained in Illinois, 40 detained in New Jersey, and 82 detained in Washington.

II. Letter from California Department of Mental Health, re: Public Records Request 08-0905, Oct., I, 2008.

12. For an in-depth discussion of the direct and indirect costs of enacting and implementing sexually violent predator legislation, see John Q. La Fond, The Costs of Enacting a Sexual Predator Law, in 4 Psychology, Public Policy and Law 468 (I998).

13. Eric S. Janus, Failure to Protect: America's Sexual Violent Predator Laws and the Rise of the Preventive State (2006) at 62, citing Washington State Institure for Public Policy, Involuntary Commitment of Sexually Violent Predators: Comparing State Laws (March 2005) and Terrence W. Campbell, Assessing Sex Offenders: Problems and Pitfalls (2004) at 6.

14. Janus, supra note 13, at 114. Janus writes that in 2004, California spent more than $\$ 78$ million to lock up 535 predators, while at the same time providing "no substantial sex offender treatment for the seventeen thousand sex offenders in its prisons." Id. at II5. Similarly, in 2004, Minnesota spent $\$ 26$ million to lock up 235 predators. That same year, pecuniary 
the public continues to demand that SVP programs be expanded. In 2006, Californians passed Proposition 83, which lowered the standard for committing individuals as sexually violent predators. ${ }^{\text {is }}$ That same year, New Hampshire enacted a sexually violent predator law, ${ }^{16}$ and Congress passed the Adam Walsh Child Safety and Protection Act, which allowed the civil commitment of individuals in federal custody. ${ }^{17} \mathrm{New}$ York enacted its sexually violent predator law in $2007 . .^{18}$

Although sexually violent predator laws are popular with the public because they keep offenders off the streets, they have been criticized. Some argue that SVP laws undermine the Constitution's due process protections by inappropriately blurring the line between punishment and civil commitment. ${ }^{19}$ Others contend that they are radically inefficient: taking resources away from addressing the majority of sex offenses, those committed by acquaintances and loved ones, and focusing them instead on heinous, highly visible but also extremely rare events. ${ }^{20}$ Still others argue that the laws have profound implications in terms of expanding state power and violating basic liberties, ${ }^{21}$ reshaping our notions of justice, ${ }^{22}$ and undermining our collective morality. ${ }^{23}$ Others step back and see SVP laws as an example of a "new penology," one that prioritizes the management of risk. They criticize this actuarial approach for "accentuating the prejudices and biases that are built into the criminal code ${ }^{24}$ and for treating offenders as objects. ${ }^{25}$

problems forced the state to propose cutting 137 of its 778 police officers and actually to eliminate roo probation officer positions despite rising caseloads, and it cut its funding for domestic violence and sexual violence prevention programs by $\$ 3.6$ million per year. Id.

15. Jenifer Warren, Judge Blocks Part of Sex Offender Law, Los Angeles Times, Nov. 8, 2006, at I, latimes.com.

16. New Hampshire Revised Statutes Annotated, Title X, Chapter 135-E-9-12.

17. Candace Rondeaux, Loudoun's 98 Sex Offenders Face New Federal Restrictions, Washington Post, Aug. 3, 2006, at To3.

I8. 2007 N.Y. ALS 7; 2007 N.Y. Laws 7; 2007 N.Y.S.N. 3318.

19. Janus, supra note 13, at 5-6, 18-20.

20. Id. at $46-93$.

2I. Id. at 107-9.

22. Bernard E. Harcourt, Against Prediction: Profiling, Policing, and Punishing in an Actuarial Age 32 (2008).

23. Robert F. Schopp, Bad or Mad? Sex Offenders and Social Control, in Protecting Sociery from Sexually Dangerous Offenders: Law, Justice and Therapy i6s (Bruce J. Winick \& John Q. LaFond eds., 2003).

24. Harcourt, supra note 22, at 190.

25. Janus, supra note 13 , at 21. 
This paper explores some of these criticisms. In section I, I begin by questioning the empirical underpinning of the laws - the belief that sex offenders will continue to reoffend ${ }^{26}$ In pressing for the passage of sexual offender legislation, advocates and lawmakers contend that sexual offenders will have a difficult if not impossible time controlling themselves. ${ }^{27}$ Implicit is the assumption that sex offenders have a high recidivism rate. This premise is contradicted by recent recidivism data published by the U.S. Department of Justice, which found that within three years of being released from prison, only 5.3 percent of 9,69I convicted sex offenders were arrested for a new sex offense. ${ }^{28}$

I then expand on Feeley and Simon's notion of the "new penology." ${ }^{29}$ Feeley and Simon argue persuasively that this focus on risk assessment and actuarial instruments reflects a profound shift in American law, from a focus on individual responsibility to managing and controlling dangerous groups.$^{30}$ Inherent in this new penology is the belief that by "using the most rigorous and advanced social scientific methods," ${ }^{31}$ we can accurately predict risk. In my discussion, I show that even the most advanced scientific instruments are not very good at predicting sexual recidivism. I focus on the Static-99 because it is one of the most commonly used instruments in sexually violent predator commitments, ${ }^{32}$ and I demonstrate that it makes many mistakes.

In section II, I discuss three due process concerns that go beyond whether the SVP laws inappropriately blur the line between civil commitment and punishment. First, I argue that it is a problem of constitutional significance that the Static-99 mistakenly recommends the commitment of many who would not reoffend. Second, I discuss how the U.S. Supreme Court upheld

26. Jonathan Simon, Managing the Monstrous: Sex Offenders and the New Penology in Protecting Society from Sexually Dangerous Offenders: Law, Justice, and Therapy 301 (Bruce J. Winick \& John Q. LaFond eds., 2003).

27. Lucy Berliner, Victim and Citizen Perspectives on Sexual Offender Policy, 989 Ann. N.Y. Acad. Sci. 464, 466 (2003).

28. U.S. Department of Justice, Bureau of Justice Statistics, Recidivism of Sex Offenders Released from Prison in 1994, Nov. 2003, NCJ198281 (hereinafter DOJ).

29. Malcolm M. Feeley \& Jonathan Simon, The New Penology: Notes on the Emerging Strategy of Corrections and its Implications, 30 Criminology 449 (1992).

3o. Id. at 452 .

31. Harcourt, supra note 22, at 21 .

32. Dennis M. Doren, Stability of the Interpretative Risk Percentages for the RRASOR and the Static-99, 16 Sexual Abuse: J. Res. \& Treatment, 25, 26 (2004). 
Kansas's Sexually Violent Predator Act against a substantive due process challenge on the grounds that the Act required that an individual have a currently diagnosed mental disorder that causes him to have difficulty controlling himself. ${ }^{33}$ A finding of future dangerousness, on its own, would have been insufficient to meet this constitutional requirement. ${ }^{34}$ In its very design, however, the Static-99 does not take into account an individual's mental illness in assessing his risk of reoffense; thus using it to justify commitment poses a serious due process problem.

Finally, in section III, I ask whether another currently available actuarial instrument might be able to address some of these problems. I look at a number of prominent instruments, and I conclude they all suffer from similar deficiencies as the Static 99.

\section{A CRITICAL LOOK AT THE SEXUAL VIOLENT PREDATOR LAWS}

\section{A. How Dangerous Are They?}

Underlying sexual predator legislation is the belief that sex offenders will continue to reoffend. ${ }^{35}$ They lurk everywhere, hunting for victims in schoolyards and on playgrounds, waiting for their opportunity to pounce. Like animals, they are incapable of controlling themselves and will continue to prey on innocent women and children unless they are locked away forever. In this section, I will question the veracity of the belief that sex offenders will inevitably reoffend. In so doing, I do not intend to diminish the horror of sex crimes or the pain that victims suffer. Nor do I mean to trivialize the unconscionable brutality of offenders like Earl Shriner.

In 2003, the U.S. Department of Justice (DOJ) released a report studying the recidivism of sex offenders released in $1994 \cdot{ }^{36}$ Recidivism was defined as rearrest for a new sex crime within three years, but research shows that offenders commit more crimes than are reflected by their arrest

33. Kansas v. Hendricks, 521 U.S. 346 at 358 (1996).

34. Id.

35. For a detailed discussion of the misconceptions underlying sex offender policies, see Jill S. Levenson \& Davi A. D’Amora, Social Policies Designed to Prevent Sexual Violence, I8 Crim. Just. Pol'y Rev. 168, 175-80 (2007).

36. DOJ, supra note 28, see Addendum 1 . 
records. ${ }^{37}$ The reality is that recidivism studies can never tell us the true rate of reoffending. To begin with, not all crimes are reported. (The problem of underreporting will be discussed in further detail below.) In addition, some people are arrested for, and even convicted of, crimes they didn't commit.

The DOJ study followed 9,691 sex offenders released from prison in fifteen states, ${ }^{38}$ which was the entire population of sex offenders released in 1994, out of 272,III total prisoners released from these fifteen states. Of these, 3,115 had been convicted of rape, 6,576 of sexual assault, 4,295 of child molestation, and 443 of statutory rape. ${ }^{39}$ Of the convicted sex offenders, 517 or 5.3 percent were rearrested for a new sex crime within three years after release. ${ }^{40}$ During that same three-year period, 5.o percent of convicted rapists were rearrested for a new sex crime. ${ }^{41}$ Finally, I4I or 3.3 percent of the convicted child molesters were arrested for another sex crime against a child. ${ }^{42}$

It is important to note that researchers continued to track released offenders during the entire three-year period. If, for instance, a person was rearrested for burglary and then later for rape, both of these arrests would have been recorded. Thus within the entire three-year period, only 5.3 percent of sex offenders were rearrested for a new sex crime. ${ }^{43}$

Convicted sex offenders were significantly more likely to be arrested for a new sex crime than released offenders who had not been convicted of a sex crime. ${ }^{44}$ Of released non-sex offenders, 1.3 percent were rearrested for a

37. Alfred Blumstein, Jacqueline Cohen, Jeffrey A. Roth \& Christy A. Visher, eds., I Criminal Careers and "Career Criminals" 55 (1986). "Rearrest forms a conservative measure of reoffending because many crimes do not result in arrest.... While some sex offenders in this study probably committed a new sex crime after their release and were not arrested or convicted, the study cannot say how many." Of course, not all those people are actually guilty, which will partially offset at least some of those who committed a new crime but were not arrested. DOJ, supra note 28, at 6 .

38. Arizona, Maryland, North Carolina, California, Michigan, Ohio, Delaware, Minnesota, Oregon, Florida, New Jersey, Texas, Illinois, New York, and Virginia. DOJ, supra note 28 , at I.

39. Id.

40. Id.

4I. Id. at 24 .

42. Id.

43. Id. at 8.

44. For a detailed discussion of the recidivism differences between different types of sex offenders as well as between sex offenders and non-sex offenders, see Patrick Lussier, The Criminal Activity of Sexual offenders in Adulthood: Revisiting the Specilization Debate, 17 Sexual Abuse: J. Res. \& Treatment 269 (2005). 
sex crime within three years after release. ${ }^{45}$ Less than 0.5 percent of non-sex offenders were rearrested for a new sex crime against a child. ${ }^{46}$

For other types of crimes, sex offenders were less likely to be rearrested than non-sex offenders. Of sex offenders released in 1994, 43 percent were arrested for a new crime within three years. In contrast, 68 percent of nonsex offenders released in 1994 were arrested for a new crime within three years. ${ }^{47}$ (See Appendix A for a closer look at the DOJ findings.)

This paper will be focusing on the DOJ study because it is the largest, most recent study of sex offender recidivism in the United States, but it is worth noting that other studies have come to similar conclusions. ${ }^{48}$ In 1998, Hanson and Bussiere did a meta-analysis of 6I studies from six different countries including the United States. ${ }^{49}$ They found that over an average follow-up time of four to five years, the sex offense recidivism rate was 13.4 percent. ${ }^{50}$ In 2007 , Sample and Bray used arrest data from 1990-1997 collected by the Illinois State Police. ${ }^{51}$ They found that less then 4 percent of convicted child molesters were rearrested for any sex offense within one, three, and five years after release from custody. ${ }^{52}$ They also found that about 7 percent of convicted rapists were rearrested for any sex offense within the same period..$^{53}$

Other studies have found significantly higher recidivism rates. For instance, Hanson, Scott, and Steffy studied the long-term recidivism of I9I child molesters released from a maximum security, provincial correctional institution in Ontario, Canada. ${ }^{54}$ Their recidivism rate, as defined by conviction for a new sex crime over a fifteen- to thirty-year period, was 35.I percent. ${ }^{55}$ This study will be discussed in more detail below.

45. DOJ, supra note 28 , at $\mathrm{I}$.

46. Id.

47. Id. at $1-2$.

48. For a discussion of the difficulties in studying sex offender recidivism, see Lita Furby, Mark R. Weinrott \& Lyn Blackshaw, Sex Offender Recidivism: A Review, os Psychol. Bull. 3-30 (I989).

49. R. Karl Hanson \& Monique T. Bussiere, Predicting Relapse: A Meta-Analysis of Sexual Offender Recidivism Studies, 66 J. Consulting \& Crim. Psychol. 348, 350 (1998).

5o. Id. at 357.

51. Lisa L. Sample \& Timothy M. Bray, Are Sex Offenders Different? An Examination of Rearrest Patterns, 17 Crim. Just. Pol'y Rev. 83 (2006).

52. Id. at 95 .

53. Id.

54. R. Karl Hanson, Heather Scott \& Richard A. Steffy, A Comparison of Child Molesters and Non-Sexual Criminals: Risk Predictors and Long-Term Recidivism, 32 J. Res. Crime \& Delinq. 325, 327 (1995).

55. Id. at 332 . 


\section{The Question of Underreporting}

The DOJ study cited above reports the number of sex offenders who were rearrested for a new sex crime within three years of release from prison. However, it does not provide data on the number of offenders who committed crimes that were never detected by law enforcement. Many theorists contend that the amount of underreporting in sex cases is high. ${ }^{56}$ Sloan, Fisher, and Cullen conducted a national study of college students in which they found that only 22 percent of rapes and 17 percent of sexual assaults were reported to local law enforcement, campus police or security, or other authorities. ${ }^{57}$ A more recent study by Fisher, Daigle, Cullen, and Turner found that only 4.5 percent of students whom they classified as having been raped reported it to the police, and an additional 3.2 percent reported it to campus authorities. ${ }^{58}$ Fisher et al. acknowledge that not all of the incidents that they classify as sexual victimizations would constitute crimes. ${ }^{59}$

The National Crime Victimization Survey (NCVS) estimates crime victimization across the United States using a nationally representative sample of households. ${ }^{60}$ Every year, approximately 135,500 people (twelve years old and above) from 76,000 households are interviewed about the frequency, characteristics, and consequences of criminal victimization within the United States. ${ }^{61}$ The U.S. Bureau of Justice Statistics (BJS) then uses these interviews to estimate the extent of crime victimization. During the period studied by the DOJ, reporting rates for rape and sexual assault ranged from

56. Mary P. Koss, Christine A. Gidycz \& Nadine Wisniewski, The Scope of Rape: Incidence and Prevalence of Sexual Aggression and Victimization in a National Sample of Higher Education Students, 55 J. Counseling \& Clinical Psychol. 162-70 (1988); John J. Sloan III, Bonnie S. Fisher \& Francis T. Cullen, Assessing the Student Right to Know and Campus Security Act of 1999: An Analysis of the Victim Reporting Practices of College and University Students, 43 Crime and Delinquency 148-68 (1997); Jody Clay-Warner \& Callie Harbin Burt, Rape Reporting after Reforms: Have Times Really Changed?, II Violence against Women I50 (2005); Bonnie S. Fisher, Leah E. Daigle, Francis T. Cullen \& Michael G. Turner, Reporting Sexual Victimization to the Police and Others: Results from a National-Level Study of College Women, 30 Crim. Just. \& Behav. 6 (2003). Furby et al., supra note 48 , at 9 .

57. Sloan et al., supra note 56.

58 . Fisher et al., supra note 56 , at 25 .

59. Id. at 19.

6o. National Crime Victimization Survey Resource Guide, National Archive of Criminal Justice Data, http://www.icpsr.umich.edu/NACJD/NCVS/.

6I. Bureau of Justice Statistics, National Crime Victimization Survey (NCVS), http:// bjs.ojp.usdoj.gov/index.cfm?ty=dcdetail\&iid=245. 
25.7 percent to 56.8 percent. In 1994 , for instance, BJS estimates that 36.1 percent of rapes and 40.7 percent of sexual assaults were reported to the police. ${ }^{62}$ In $1995,35.3$ percent of rapes and 27.9 percent of sexual assaults were reported to the police. ${ }^{63}$ In 1996, 40.6 percent of forcible and 24.5 percent of sexual assaults were reported to the police. ${ }^{64}$ Finally, in 1997 , 46.4 percent of all rapes were reported to the police, and 9.3 percent of all attempted rapes were reported to the police. ${ }^{65}$

Reporting rates have remained relatively consistent since that time. In $1998,28.1$ percent of all rapes and 35.9 percent of sexual assaults were reported to the police. ${ }^{66}$ In $1999,37.5$ percent of rapes and 23.6 percent of sexual assault were reported to the police. ${ }^{67}$ In $2000,57.9$ percent of rapes and 30.2 percent of sexual assaults were reported to the police. ${ }^{68}$ In $200 \mathrm{I}$, 43.4 percent of rapes and 34.4 percent of sexual assaults were reported to the police. ${ }^{69}$ In 2002, 57.3 percent of all rapes and 47.8 percent of sexual assaults were reported to the police. ${ }^{70}$ In $2003,33.2$ and 46.8 percent of all rapes and percent of sexual assaults were reported to the police. ${ }^{71}$ And in 2004, the BJS estimated that 56.8 percent of all forcible rapes and 25.7 percent of all sexual assaults were reported to the police. ${ }^{72}$ In 2005 , the BJS estimated that 45.2 percent of all forcible rapes and 30.2 percent of all sexual assaults were reported to the police in 2005 . In 2006, the BJS estimated that 41.4 percent

62. DOJ, Criminal Victimization in the United States, 1994 Statistical Tables (May 1997), NCJ162126, Table 91.

63. DOJ, Criminal Victimization in the United States, 1995 Statistical Tables (May 2000), NCJi7II29, Table 91.

64. DOJ, Criminal Victimization in the United States, 1997 Statistical Tables (Sept. 2000), NCJ174445, Table 91.

65. DOJ, Criminal Victimization in the United States, 1997 Statistical Tables (Sept. 2000), NCJ174446, Table 91. The strikingly low percentage of those reporting sexual assaults may be explained by the fact that the estimate was made based on approximately ten or fewer sample cases.

66. DOJ, Criminal Victimization in the United States, 1998 Statistical Tables, Table 91.

67. DOJ, Criminal Vicrimization in the United States, 1999 Statistical Tables, Table 91.

68. DOJ, Criminal Vicrimization in the United States, 2000 Statistical Tabies, Table 91.

69. DOJ, Criminal Victimization in the United States, 200I Statistical Tables, Table 91.

70. DOJ, Criminal Victimization in the United States, 2002 Statistical Tables, Table 91.

71. DOJ, Criminal Victimization in the United States, 2003 Statistical Tables, Table 9I. The rape estimate was given an asterix because it was calculated based on to or fewer rapes.

72. DOJ, Criminal Victimization in the United States, 2004 Statistical Tables (June 2006), NCJ213257, Table 91. 
of all forcible rapes and sexual assaults were reported to the police. ${ }^{73}$ Finally, in 2007 , BJS estimated that 53.9 percent of rapes and 28.6 percent of sexual assaults were reported to the police. ${ }^{74}$

Underreporting is a problem for all crimes, not only sex offenses. Looking at the last three years-in 2005, the NCVS found that $\$ 2.4$ percent of robberies, 62.4 percent of aggravated assaults, and 56.3 percent of household burglaries were reported to the police. ${ }^{75}$ In 2006, the NCVS found that 56.8 percent of robberies, 59.6 percent of aggravated assaults, and 49.5 percent of household burglaries were reported to the police. ${ }^{76}$ Finally, in 2007, the NCVS found that 65.6 percent of robberies, 57.2 percent of aggravated assaults, and 50. I percent of household burglaries were reported to the police. ${ }^{77}$

There are many reasons why cases may not be brought to the attention of law enforcement. ${ }^{78}$ Family members or friends commit most sex offenses, and so victims may not want to risk getting someone they care about in trouble. ${ }^{79}$ In addition, a victim may be embarrassed or blame him or herself for what occurred. She or he may be distrustful of the police or the court system. A victim might also fear reprisal or the possible repercussions to her assailant. Alternatively, the victim may not believe that what happened was a crime. If the victim is a child, he or she might have told a parent or guardian who did not take the allegation seriously, especially if the accused is a close family member or trusted friend.

Although these studies show that underreporting is a serious problem, they do not necessarily reflect on the accuracy of the recidivism studies

73. Michael Rand \& Shannan Catalano, Bureau of Justice Statistics Bulletin, Criminal Victimization, 2006, Dec. 2007, NCJ219413 at 5. Although changes were made to the NCVS in 2006 that prevent comparison of national-level estimates from previous years, it is still worth reporting prior findings. Id. at $\mathrm{I}$.

74. DOJ, Criminal Victimization in United States, 2007 Statistical Tables, Table 91. Once again, BJS put an asterix next to the rape estimation because it was based on just 1o or fewer cases.

75. Rand \& Catallano, supra note 73 , at 5 .

76. Id.

77. DOJ, supra note 74, Table 9i.

78. See Fisher et al, supra note 56, at 9-15.

79. "About 69 percent of female victims of rape were victimized by someone known to them. When rape and sexual assault are combined, nearly 60 percent of such crimes were reported by victims to have occurred in their own home or at the home of a friend, relative, or neighbor." Janus, supra nore 13 , at 46 (citations omitted). See also Levenson \& D'Amora, supra note 35 , at 178 . 
cited above. For these studies to be relevant, the perpetrators not being reported must be previously convicted sex offenders.

One direct way of determining whether sex crimes by convicted sex offenders are underreported relative to those committed by first-time offenders is the proportion of new arrests for sex crimes committed by individuals who were not previously convicted of a sex offense. The $2003 \mathrm{DOJ}$ study found that 513 released sex offenders were arrested for a new sex crime as compared with 3,329 released non-sex offenders arrested for a new sex crime. ${ }^{80}$ Thus among released individuals arrested for sex crimes, 86.5 percent had not been convicted of a prior sex offense.

Indeed, it would not be surprising if underreporting was less prevalent among convicted sex offenders. The Jacob Wetterling Act requires states to register sex offenders for at least ten years after release from prison, and the Pam Lynchner Act amended this requirement so that certain sex offenders must now register for the rest of their lives. ${ }^{81}$ Megan's Law requires that this information be made available to the public. ${ }^{82}$ Furthermore, when sex offenders are released from custody, they are often placed on strict parole or probation supervision. If one of these individuals committed a sex crime, it seems more likely that a victim's report would be taken seriously.

\section{Is the DOJ Recidivism Study Applicable to Sexually Violent Predators?}

The DOJ calculated the recidivism rate of 9,691 sex offenders released from prison in 1994 who had been convicted of a number of crimes including rape (forcible and statutory), child molestation, and sexual assault. Some of these individuals had no prior convictions; others had several. Before the DOJ findings can be applied to sexually violent predators, a critical question must be answered: Are sexually violent predators similar to the general sex-offending population?

When people think of a sexually violent predator, most think of someone like Richard Allen Davis, the repeat sex offender who kidnapped Polly Klaas

8o. DOJ, supra note 28 , at $\mathbf{I}$.

8I. DOJ, Office of the Attorney General, A.G. Order No. 2196-98, RIN IIO5-AA56: Megan's Law; Final Guidelines for the Jacob Wetrerling Crimes Against Children and Sexually Violent Offender Registration Act, as Amended (signed by Janet Reno on December I0, 1998).

82. Office of Justice Programs, Bureau of Justice Assistance, Overview and History of the Jacob Wetterling Act. 
from her bedroom window, then raped and murdered her ${ }^{83}$ The reality, however, is quite different. To begin with, no state requires that a person have committed multiple crimes to qualify as a sexually violent predator. Indeed, the laws specifically state that one conviction of a qualifying offense is enough.

Even more striking, although states require that an individual be convicted of at least one "sexually violent offense," what is classified as such need not be either sexual or violent. ${ }^{34}$ Nine states do not even require any actual sexual contact between the sexually violent predator and the victim. In Wisconsin, for instance, it is a sexually violent offense for a person to attempt to entice a minor under the age of eighteen into a car, building, room, or secluded place with the intention of giving that minor a controlled substance. In Iowa, it is a sexually violent offense to knowingly share in the proceeds of a premise of prostitution involving minors.

In addition, nineteen states classify certain sexual contact as a sexually violent offense even if there was no violence. In Arizona, for example, sexual intercourse with a person under the age of eighteen is defined as a sexually violent offense, and in Illinois it is a sexually violent offense for anyone seventeen years or older to solicit a person younger than seventeen to have sex. Although committing a lewd act on a child under the age of sixteen is not considered a violent offense under South Carolina law, it does qualify as a sexually violent offense for the purposes of an SVP commitment. Also of note, South Carolina classifies all sodomy as a sexually violent offense regardless of age or consent.

\section{Discussion}

As Table I shows, individuals can be committed as sexually violent predators for conduct that is neither sexual nor violent. It is of critical importance to find out which crime(s) individuals committed that led to their designation as SVPs, but I searched and could not find any source for this information. Thus I wrote to each of the states directly and requested this data, but none provided it. The DOJ did not think it necessary to distinguish

83. Bob Egelko, Death Sentence Upheld for Polly Klaas' Killer, SFGate.com, June 2, 2009, http://articles.sfgate.com/2009-06-02/bay-area/17208285_t_polly-klaas-richard-allendavis-mike-meese.

84. Nor must the offense have actually been completed; in most states, attempt, solicitation, facilitation, or conspiracy to commit a sexually violent offense is enough. A.R.S. $\$$ 36-370I, 6(c) (2008). 
Table 1. Some offenses deemed to be sexually violent in the United States

\begin{tabular}{|c|c|c|c|}
\hline State & Sexually violent offense & $\begin{array}{l}\text { Is sexual contact with } \\
\text { the victim required? }\end{array}$ & $\begin{array}{l}\text { Is violence } \\
\text { against the } \\
\text { victim required? }\end{array}$ \\
\hline Arizona $^{\circ}$ & $\begin{array}{l}\text { Sexual intercourse or oral contact } \\
\text { with a person under the age } \\
\text { of } 18 \text {. }\end{array}$ & Yes & No \\
\hline Californiab & $\begin{array}{l}\text { Touching a person with the specific } \\
\text { intent to arouse, appeal to, or grat- } \\
\text { ify lust, passions, or sexual desire. }\end{array}$ & $\begin{array}{l}\text { Above the clothes is } \\
\text { sufficient. }\end{array}$ & $\begin{array}{l}\text { Not if the victim is } \\
\text { younger than } 14 .\end{array}$ \\
\hline Florida ${ }^{\circ}$ & $\begin{array}{l}\text { Lewd or lascivious offenses com- } \\
\text { mitted on or in the presence of a } \\
\text { child younger than } 16 \text {. }\end{array}$ & $\begin{array}{l}\text { No, includes soliciting a } \\
\text { person under the age } \\
\text { of } 16 \text { to commit a } \\
\text { lewd or lascivious act. } \\
\text { No, includes intention- } \\
\text { ally masturbating or } \\
\text { exposing genitals in } \\
\text { a lewd and lascivi- } \\
\text { ous way to a person } \\
\text { under } 16 \text {. }\end{array}$ & No \\
\hline lowad & $\begin{array}{l}\text { Persuading, arranging, or causing } \\
\text { a minor to become a prostitute. } \\
\text { Maintaining a premises for the pur- } \\
\text { pose of prostitution involving mi- } \\
\text { nors or knowingly sharing in the } \\
\text { income of such a premises. }\end{array}$ & No & No \\
\hline Kansas $^{\circ}$ & $\begin{array}{l}\text { Enticing a child between the ages } \\
\text { of } 14 \text { and } 16 \text { to submit to an } \\
\text { unlawful sexual act. } \\
\text { Inviting, persuading, or attempting } \\
\text { to persuade a child between } \\
\text { the ages of } 14 \text { and } 16 \text { to enter } \\
\text { any vehicle, building, room, or } \\
\text { secluded place with the intent } \\
\text { to commit an unlawful sexual } \\
\text { act upon the child. }\end{array}$ & No & No \\
\hline Illinois' & $\begin{array}{l}\text { Any person age } 17 \text { or older who } \\
\text { solicits a child younger than } \\
17 \text { to engage in an act of sexual } \\
\text { penetration or sexual conduct. }\end{array}$ & No & No \\
\hline Massachusetts & $\begin{array}{l}\text { Lewd and lascivious acts with a } \\
\text { child under the age of } 16 \text {. }\end{array}$ & Yes & No \\
\hline Minnesota" & $\begin{array}{l}\text { Sexual contact with a minor who } \\
\text { is younger than } 13 \text { if the per- } \\
\text { petrator is no more than } 36 \\
\text { months older than the minor. } \\
\text { Sexual contact with a minor who } \\
\text { is at least } 13 \text { but younger than } \\
16 \text { if the perpetrator is at least } \\
48 \text { months older. }\end{array}$ & Yes & No \\
\hline Missoun' & $\begin{array}{l}\text { Subjecting another person who is } \\
\text { less than } 17 \text { years of age to } \\
\text { sexual contact. }\end{array}$ & Yes & No \\
\hline
\end{tabular}


Table 1. Continued

\begin{tabular}{|c|c|c|c|c|}
\hline State & Sexually violent offense & $\begin{array}{l}\text { Is sexual contact } \\
\text { the victim require }\end{array}$ & with & $\begin{array}{l}\text { Is violence } \\
\text { against the } \\
\text { victim required? }\end{array}$ \\
\hline \multirow[t]{2}{*}{ Nebraska } & $\begin{array}{l}\text { Knowingly restraining a minor } \\
\text { under the age of } 12 \text { without } \\
\text { legal authority. }\end{array}$ & No & & Yes \\
\hline & $\begin{array}{l}\text { Sexual contact with a minor } \\
14 \text { years of age or younger if } \\
\text { the defendant is } 19 \text { or older. }\end{array}$ & Yes & & No \\
\hline New Hampshire & $\begin{array}{l}\text { A burglary committed with the } \\
\text { intention of committing a } \\
\text { sexual assault. }\end{array}$ & No & & No \\
\hline New Jersey & $\begin{array}{l}\text { Sexual penetration of a victim } \\
\text { who is younger than } 13 \text {. }\end{array}$ & Yes & & No \\
\hline New York' & $\begin{array}{l}\text { Sexual contact with a person who } \\
\text { is younger than } 11 .\end{array}$ & Yes & & No \\
\hline \multirow[t]{2}{*}{ North Dakotam } & $\begin{array}{l}\text { Touching the sexual or intimate } \\
\text { parts of a person under the age } \\
\text { of } 15 \text { for the purpose of arous- } \\
\text { ing or satisfying sexual or } \\
\text { aggressive desires. }\end{array}$ & Yes & . & No \\
\hline & $\begin{array}{l}\text { Touching the sexual or intimate } \\
\text { parts of a minor if it is done by } \\
\text { an adult with the intent to } \\
\text { arouse or satisfy sexual or } \\
\text { aggressive desires. }\end{array}$ & Yes & . & No \\
\hline \multirow[t]{2}{*}{ Pennsylvania" } & $\begin{array}{l}\text { Indecent contact with another } \\
\text { who is younger than } 13 \text {. }\end{array}$ & Yes & & No \\
\hline & $\begin{array}{l}\text { Indecent contact with a 16-year- } \\
\text { old if the perpetrator is at least } \\
4 \text { years older than the victim. }\end{array}$ & Yes & & No \\
\hline \multirow[t]{2}{*}{ South Carolina ${ }^{\circ}$} & Sodomy. & Yes & & No \\
\hline & $\begin{array}{l}\text { Committing a lewd act on a child } \\
\text { under the age of } 16 \text {. }\end{array}$ & Yes & . & No \\
\hline \multirow[t]{2}{*}{ Texas $^{p}$} & $\begin{array}{l}\text { Sexual contact (above or below } \\
\text { the clothing) with a child } \\
\text { younger than } 17 .\end{array}$ & Yes & & No \\
\hline & $\begin{array}{l}\text { Showing anus or genitals to a } \\
\text { child with the intention of arous- } \\
\text { ing self or child. }\end{array}$ & No & & No \\
\hline Virginia ${ }^{9}$ & $\begin{array}{l}\text { Carnal knowledge, without the } \\
\text { use of force, of a victim who is } \\
\text { at least } 13 \text { years old but } \\
\text { younger than } 15 \text { if the defen- } \\
\text { dant is at least } 5 \text { years older } \\
\text { than the victim. }\end{array}$ & Yes & & No \\
\hline Washington' & $\begin{array}{l}\text { Sex with a person who is older } \\
\text { than } 12 \text { but younger than } 14 \text { if } \\
\text { the perpetrator is at least } 36 \\
\text { months older than the victim } \\
\text { and they are not married. }\end{array}$ & Yes & & No \\
\hline
\end{tabular}


Table 1. Continued

\begin{tabular}{|c|c|c|c|}
\hline State & Sexually violent offense & $\begin{array}{l}\text { Is sexual contact with } \\
\text { the victim required? }\end{array}$ & $\begin{array}{l}\text { Is violence } \\
\text { against the } \\
\text { victim required? }\end{array}$ \\
\hline & $\begin{array}{l}\text { Sexual contact (touching of the } \\
\text { sexual or intimate parts of an- } \\
\text { other for the purpose of sexual } \\
\text { gratification) with someone who } \\
\text { is younger than } 14 .\end{array}$ & Yes & No \\
\hline \multirow[t]{2}{*}{ Wisconsin ${ }^{\circ}$} & $\begin{array}{l}\text { Sexual intercourse or sexual con- } \\
\text { tact with someone who is under } \\
\text { the age of } 16 .\end{array}$ & Yes & No \\
\hline & $\begin{array}{l}\text { Enticement of a child: causes or at- } \\
\text { tempts to cause anyone younger } \\
\text { than } 18 \text { to go into any vehicle, } \\
\text { building, room, or secluded place } \\
\text { with the intention of, among other } \\
\text { things, having sex with that minor, } \\
\text { exposing a sex organ to the mi- } \\
\text { nor, or giving or selling the minor } \\
\text { a controlled substance. }\end{array}$ & No & No \\
\hline
\end{tabular}

-Arizona Revised Statute § 36-3701, 6(a) (2008).

'California Penal Code $§ 288$ (a); id. at section 6600.1 (b). Before the passage of Proposition 83, there was a requirement of substantial sexual contact; however this is no longer the case. See http://www.sos. ca.gov/elections/vig_06/general_06/pdf/proposition_83/entire_prop83.pdf. at 135.

'Florida Statute $\$ 800.04$ (2009).

dowa Code $§ 229 A .2$ (2008) b, 4, d; and $\$ 725.3$ (2008).

*Kansas Statutes Archive \$59-29a02 (2006) d, 6; and \$21-3510.

'725 Illinois Compiled Statites 207/5; and 720 ILCS 5/11-6 (2009).

"Annotated Laws of Massachusetts GL ch. 6 \$178c; and ch. $272 \S 35 \mathrm{~A}$.

"Minnesota Statute $\S 2538.02$ (2009); and $\S 609.345$.

\ 632.480 Revised Statutes of Missouri (2008); and $\S 566.068$ R.S.Mo. (2009)

' In New Hampshire, a sexually violent offense is limited to capital murder or first degree murder while in the commission or attempted commission of felonious sexual assautt, aggravated felonious sexual assault, kidnapping where the offender confined the crime with the purpose to commit sexual assault, burglary where the offender entered the building with the intention of committing sexual assault, an attempt, criminal solicitation, or conspiracy to commit any of the above offenses. Revised Statutes Annotated $\$ 135-\mathrm{E}: 2, \mathrm{XI}$.

"New Jersey Statutes § 30:4-27.26; § 2C:14-3 (2009); and § 2C:14-2 (2009).

'New York CLS Correc. $\$ 168-a$ (2009) NY (3),(a), (i); CLS Penal $§ 130.65$ (2009).

mNorth Dakota Cent. Code, § 25-03.3-01 (7), (9) (a) (4), and (7) (2008) .

"18 Pa.C.S. $\$ 3126$ (7), and (8) (2009).

'South Carolina Code Ann. $\$ 44-48-30$ (2007); $\$ 16-15-120$ (2008); and $§ 16-15-140$ (2008). Although \$ 16-15-140 (2008) is defined as nonviolent for criminal purposes, it qualifies one to be committed as a sexually violent predator. Beaver v. State (2007) 372 S.C. 272; 642 S.E.2d 578; 2007 S.C. LEXIS 71. PTexas Health \& Safety Code $\$ 841.002$ (8); Texas Penal Code $\$ 21.11$ (2009). It is an affirmative defense if the perpetrator is no more than three years older than the victim and of the opposite sex, and if he did not use duress, force, or a threat against the victim, and if he was not registering as a sex offender or did not have a reportable conviction or adjudication.

$\checkmark V$ irginia Code Ann. $§ 9.1-902$.(E) (1) (2009); and $\S 18.2-63$ (2009). According to $\S 18.2-63$ (C) (2009), "carnal knowledge' includes the acts of sexual intercourse, cunnilingus, fellatio, anilingus, anal intercourse, and animate and inanimate object sexual penetration."

'Revised Code of Washington (ARCW) $\$ 71.09 .020$ (15); $\$ 9 A 44.076$ (2009); and $§ 9 A 44.100$ (2009). -Wisconsin Statute $\$ 980.01$ (6)(a); $\$ 948.02$ (2009); $\$ 980.01$ (6)(a); and §948.07 (2009). 
prospective sexually violent predators from the general sex-offending population, and my analysis accords with the DOJ's judgment. After examining the legal definitions of those offenses that would qualify someone for commitment as a sexually violent predator, I could not find any grounds to distinguish SVPs from the general sex-offending population. As a result, it is appropriate to use the DOJ findings in analyzing the recidivism rates of sexually violent predators.

\section{B. The Limited Hope of the New Penology: The Difficulty in Predicting Future Dangerousness}

In 1992, Malcolm Feeley and Jonathan Simon coined the term "the new penology" to describe the move to risk assessment and actuarial prediction in the criminal justice system. Actuarial instruments that assess sex offender recidivism risk are used in a variety of procedures, including civil commitment hearings, sentencing recommendations, and parole determinations. ${ }^{85}$ Researchers like Levenson and D'Amora argue that risk assessment should become even more of an integral part of sex offender policy as it "allows us to identify the most dangerous sex offenders, and to apply the most intensive interventions to those who need the greatest level of supervision, treatment, and restriction. It is unfortunate that most policy initiatives have not incorporated risk assessment strategies into their implementation." ${ }_{86}$

In his recent book, Against Prediction: Profling, Policing and Punishing in an Actuarial Age, Bernard E. Harcourt criticizes the actuarial trend in criminal law. He contends that actuarial methods shape our notions of just punishment, leading us to prioritize incapacitation over other theories. ${ }^{87}$ Harcourt argues such methods "serve only to accentuate the ideological dimension of the criminal law ... hardening the purported race, class, and power relations between certain offenses and certain groups." ${ }^{\text {88 }}$ Yet he does not question the ability of actuarial instruments to meet the promise of the new penology. Instead, Harcourt argues that they should only be used in narrow circumstances, "when dealing with child molesters, terrorists, and serial killers."

85. Doren, supra note 32.

86. See Levenson \& D'Amora, supra note 35, at 177.

87. Harcourt, supra note 22 , at 32.

88. Id. at 190 .

89. Id. at 191. 
The inquiry I pursue here is different. I do not ponder the social and philosophical costs of the new penology. Instead, I question its core justification. Can the new penology even keep its promise of scientific, objective, and reliable sex offender risk assessment?

\section{Predicting Future Dangerousness}

In Kansas $v$. Hendricks, the Court upheld the Kansas SVP statute in a due process challenge because it "unambiguously require[d] a finding of future dangerousness to one's self or to others as a prerequisite to involuntary confinement." ${ }^{10}$ In Hendricks, ${ }^{91}$ it was easy for the jurors to make this decision. During the trial, Hendricks admitted that he was an uncured pedophile who could not control his desire to molest children. ${ }^{92}$ He testified that although he did not want to molest children, the only way he could stop was by dying. ${ }^{93}$ It is no surprise then that the Supreme Court never really considered the accuracy of making these sorts of future predictions. It simply was not a contested issue in Hendricks.

In most cases, individuals do not admit that they pose a future risk; instead, the prosecutor must prove it. There are currently two basic approaches to assessing an individual's risk of future dangerousness: clinical and actuarial. ${ }^{94}$ I will evaluate the accuracy of each.

\section{a. Clinical Assessments}

In 1978, a task force of the American Psychological Association reported:

It does appear from reading the research that the validity of psychological predictions of dangerous behavior, at least in the sentencing and release situation ... is extremely poor, so poor that one could oppose their use on the strictly empirical grounds that psychologists are not professionally competent to make such judgments. ${ }^{95}$

90. Kansas v. Hendricks, supra note 33 , at 357.

9I. Id.

92. Id. at 355 .

93. Id.

94. For a discussion of the jurisprudence of risk assessment, see John Monahan, A Jurisprudence of Risk Assessment: Forecasting Harm among Prisoners, Predators, and Patients, 92 Va. L. Rev. 391 (2007).

95. American Psychological Association, Report of the Task Force on the Role of Psychology in the Criminal Justice System, 3 Am. Psychologist 1099, IIIo (1978). 
In a clinical assessment, forensic psychologists and psychiatrists conduct interviews, review case files, and perform psychological testing, and then use that information as the basis for a clinical opinion of whether a person is likely to reoffend ${ }^{96}$ Although there is some disagreement regarding whether clinicians can accurately predict future dangerousness, ${ }^{97}$ as the quote above makes clear, most experts believe that they cannot. ${ }^{98}$ Studies have shown that clinical predictions are not much more accurate then chance. ${ }^{99}$ In a meta-analysis of ten studies (total sample size $=1,453$ ) that evaluated the predictive accuracy of clinical assessment in predicting sexual recidivism, the average correlation between clinical prediction of sex offender recidivism and actual recidivism was merely 0.10. ${ }^{100}$

One potential problem is that factors that would seem to be intuitively linked to risk, are not. For example, denial of the charges and low treatment motivation were not linked to recidivism. ${ }^{101}$ Nor were general psychological problems, ${ }^{102}$ alcohol abuse, or childhood sexual abuse a predictor for reoffending. ${ }^{103}$ Facts related to the crime like low victim empathy and degree of sexual contact were also unassociated with recidivism. ${ }^{104}$

Guided clinical assessments, however, have enjoyed slightly more predictive success. ${ }^{105}$ In a guided assessment, a clinician uses an array of risk factors that have been empirically linked to recidivism and applies them when making a prediction about a particular individual. There are no specific

96. R. Karl Hanson, What Do We Know about Sex Offender Risk Assessment, 4 Psychol., Pub. Pol'y \& L. 50, 54 (1998).

97. See Thomas R. Litwack, Actuarial Versus Clinical Assessments of Dangerousness, 7(2) Psychol., Pub. Pol'y, \& L. 409 (2001).

98. Hanson, supra note 96; John Monahan, The Clinical Prediction of Violent Behavior (1981); Vernon L. Quinsey \& Rudolf Ambtman, Variables Affecting Psychiatrists' and Teachers' Assessments of the Dangerousness of Mentally Ill Offenders, $47 \mathrm{~J}$. Consulting \& Clinical Psychol. 353-62 (1979); Vernon L. Quinsey \& Anne Maguire, Maximum Security Psychiatric Patients: Actuarial and Clinical Prediction of Dangerousness, I J. Interpersonal Violence I43-71 (1986).

99. Hanson \& Bussiere, supra note 49 , at $356 ; r=0.10$ for sexual recidivism.

10o. Hanson, supra note 96 , at 54 .

IOI. Hanson \& Bussiere, supra note 49 , at 348-362.

102. R. Karl Hanson, Kelly E. Morton \& Andrew J.R. Harris, Sexual Offender Recidivism Risk: What We Know and What We Need to Know, 989 Ann. N.Y. Acad. Sci. 154-66, 158 (2003).

103. Hanson, supra note 96 , at 56 . Hanson \& Bussiere, supra note 49 , at 353 .

I04. Hanson et al., supra note IO2, at 158.

I05. Hanson, supra note 96 , at so. 
rules regarding how to weight each factor. ${ }^{106}$ Still, guided clinical assessments have been more accurate at predicting future dangerousness then straight clinical predictions. ${ }^{107}$ In an analysis of two studies (sample size $=$ 369) that looked at the accuracy of guided clinical assessments in predicting sexual recidivism, the average correlation was $0.23 .{ }^{108}$

\section{b. Actuarial Instruments}

The most commonly accepted technique uses actuarial instruments to predict risk. These instruments have been used to predict general criminal and violent recidivism as well as sexual recidivism. Actuarial instruments use an individual's characteristics, such as age, marital status, sex of victims, and number of prior offenses to predict reoffending. To develop the instrument, researchers conduct a statistical analysis to see which attributes are related most closely to reoffending in a population of convicted sex offenders released from confinement. The statistical analysis assigns a weight to each characteristic, allowing them to be combined into a total risk score. Individuals are then scored, and that score is associated with a level of risk of reoffending.

There are several well-known actuarial instruments used to predict the risk of sexual recidivism: the Rapid Risk Assessment for Sexual Offense Recidivism (RRASOR), ${ }^{109}$ the Structured Anchored Clinical Judgment (SACJ), ${ }^{110}$ Sex Offender Risk Appraisal Guide (SORAG), "1 the Minnesota Sex Offender Screening Tool-Revised (MnSOST-R), ${ }^{112}$ and the Static-99. ${ }^{113}$ Each scale lists factors to consider and explains how to weight the significance

106. Id. at 62.

107. Hanson et al., supra note 102, at 159.

108. Hanson, supra note 96 , at 55 .

109. R. Karl Hanson, The Development of a Brief Actuarial Risk Scale for Sexual Offense Recidivism (User Report 1997-04).

IIO. D. Grubin, Sex Offending against Children: Understanding the Risk, Police Research Series Paper 99 (1998).

III. Vernon L. Quinsey, Grant T. Harris, Marnie E. Rice \& Catherine A. Cormier, Violent Offenders: Appraising and Managing Risk (1998).

112. Douglas L. Epperson, James D. Kaul, Stephen Huot, Robin Goldman \& Will Alexander, Minnesota Sex Offender Screening Tool-Revised (MnSOST-R) Technical Paper: Development, Validation, and Recommended Risk Level Cut Scores (December 2003).

113. R. Karl Hanson \& David Thornton (1999), Static-99: Improving Actuarial Risk Assessments for Sex Offenders (User Report No. 1999-02), Ottawa: Department of the Solicitor General of Canada (1999). 
of each factor. Although the instruments consider similar factors, they, differ as to how each should be weighted. ${ }^{114}$

Problems in Measuring Predictive Accuracy. One of the problems that researchers had in creating an actuarial instrument to predict sexual reoffending was the low base rate-the percentage of persons who actually reoffended. ${ }^{115}$ With such low recidivism rates, it might seem to make sense to just predict that no one would reoffend. For example, if you predicted that none of the 9,691 sex offenders studied by the DOJ would reoffend by committing a sex offense within the first three years, you would be right for 94.7 percent of them. Indeed, Karl Hanson, the creator of the Static-99 that will be discussed at length below, wrote, "If few offenders recidivate, as is often the case in sexual offender outcome studies, then the simplest way to maximize the percentage correct classified is to predict that no one will reoffend."116

Attempts at Compensating for the Low Base Rate. Complicating matters further was the fact that most of the methods ${ }^{17}$ used to evaluate predictive accuracy were dependent on the base rate or the selection ratio, the proportion of people predicted to reoffend sexually. Researchers proffered orher measures to address this problem, such as correlation coefficients, but all were dependent to some degree on base rates or selection ratios. ${ }^{118}$ Furthermore, "none of the measures is suitable for comparing the predictive accuracies of different tests when each has been used in a sample with a different base rate of the outcome in question." 11

II4. Id.

IIs. Vernon L. Quinsey, Marnie E. Rice \& Grant T. Harris, Actuarial Prediction of Sexual Recidivism, Io(I) J. Interpersonal Violence 85 (1995).

II6. Hanson, supra note 96 , at 53 .

II7. This includes false positive and false negative rates, sensitivity and specificity, positive and negative predictive power, and percent correctly classified. Marnie E. Rice \& Grant T. Harris, Violent Recidivism: Assessing Predictive Validity, 63(5) J. Consulting \& Clinical Psychol. 737-48, 737 (1995), citing R.J. Baldessarini, S. Finkelstein \& G.W. Arana, The Predictive Power of Diagnostic Tests and the Effect of Prevalence of Illness, 40 Archives Gen. Psychiatry 569-73 (1983).

II8. Rice \& Harris, supra note II7, at 737-738, citing Robert Rosenthal, How Are We Doing in Soft Psychology?, 45 Am. Psychologist 775-77 (1990); and Robert Rosenthal, Effect Sizes: Pearson's Correlation, Its Display via the BESD, and Alternative Indices, ${ }_{4} 6$ Am. Psychologist 1086-87 (1991).

I19. Rice \& Harris, id. at 738 . 
Some researchers attempted to tackle the low base rate problem by using receiver operator characteristics (ROCs) in evaluating the accuracy of their instruments. ${ }^{120} \mathrm{ROCs}$ remain constant as the base rates and selection ratios change. ${ }^{121}$ The ROC curve is the ratio of the sensitivity of the instrumenit (the true positives-the proportion of those who will reoffend, who were correctly identified by the instrument) divided by I minus the specificity of the instrument (the false positives-the proportion of those who will not reoffend, who were misclassified by the instrument). If the instrument were no better then guessing, then the area under the ROC curve would have a score of 0.5. If it were perfect at identifying reoffenders and non-reoffenders, then the area under the ROC curve would have a score of I.O.

- Some experts suggest that the accuracy of ROC scores should be interpreted as follows: less than 0.60 is low, $0.60-0.70$ is marginal, $0.70-0.80$ is modest, $0.80-0.90$ is moderate, and a score of 0.90 or above is high. ${ }^{122}$

\section{A Focus on the Static-99}

R. Karl Hanson and David Thornton created the Static- $99^{123}$ by combining together two instruments, the RRASOR ${ }^{124}$ and the SACJ-Min. ${ }^{125}$ It is the

I20. Hanson \& Thornton, supra note 113 , at 7. Another benefit to ROCs is that they allow the accuracy of instruments to be compared even if they were developed on samples with different base rates. Grant T. Harris, Marnie E. Rice, Vernon L. Quinsey, Martin L. Lalumiere, Douglas Boer \& Carọl Lang, A Multisite Comparison of Actuarial Risk Instruments for Sex Offenders, I5(3) Psychological Assessment 413 (2003).

12I. Rice \& Harris, supra note II7, at 738 .

122. Gabrielle Sjostedt \& Niklas Langstrom, Assessment of Risk for Criminal Recidivism among Rapists: A Comparison of Four Different Measures, 8 Psychol., Crime \& L. 25-40 (2002).

123. Hanson \& Thornton, supra note 113 .

124. Id. at 3. In 1998, Hanson and Bussiere conducted a meta-analysis of sexual analysis recidivism studies to find the factors most strongly correlated with sexual reoffending. They looked at data on 28,972 sexual offenders. See supra note 49. The Rapid Risk Assessment for Sex Offence Recidivism (RRASOR) was created by taking the seven factors that correlated at least 0.11 with sexual recidivism. The RRASOR was created by taking the four factors most highly correlated with sexual reoffending: prior sex offenses, any unrelated victims, any male victims, and age less than 25 . It was then tested on a new population sample. Predictive accuracy in both the development and validation samples was similar $(r=$ 0.27 ; ROC area $=0.71$ ). Hanson \& Thornton, supra note II3 at 3 .

125. Hanson \& Thornton, supra note I13 at 3-4. The Structured Anchored Clinical Judgement Minimum (SACJ-Min) uses a stage approach to predict sexual and violent 
most commonly used actuarial instrument for assessing the risk of sexual recidivism. ${ }^{126}$ In a 2002 survey of treatment programs, the Static-99 was used in about half of those surveyed, ${ }^{127}$ and the RRASOR (which contains four of the items scored on the Static-99) was used in 35 percent of programs surveyed. ${ }^{128}$

The Static-99 scores individuals on a list of seven risk factors that have been shown to be correlated with sexual recidivism: prior sex offenses (can be satisfied by arrests, charges, convictions, violation of institutional rules, or probation, parole, or conditional release violations), ${ }^{129}$ prior sentencing dates for any type of criminal offense, ${ }^{130}$ any convictions for noncontact sexual offenses, ${ }^{131}$

recidivism. Stage I considers the offender's official criminal record: prior sex offenses, current sex offenses, current nonsexual violent offenses, prior nonsexual violent offenses, and four or more prior sentencing occasions. Id. at 3. Individuals are given a score of low to high risk based on how many of these factors they have. Stage 2 considers whether certain potentially aggravating factors are present in the individual's history. These include any stranger victims, any male victims, whether the individual was never married, and whether he has conviction for noncontact sex offenses such as exhibitionism and making obscene phone calls. If two or more of these factors are present, then the individual's initial risk level is increased one level. Id. at 4. The SACJ-Min was developed and validated on populations in the United Kingdom. In the validation sample, it correlated 0.34 with sexual recidivism. Id. at 4 .

126. R. Karl Hanson, The Validity of the Static-99 with Older Sexual Offender 2005-or, Publication of the Public Safety and Emergency Preparedness Canada at 2 (2005).

127. R.J. McGrath, G.F. Cumming \& B.L. Burchard, Current Practices in Sexual Abuser Management: The Safer Society 2002 Nationwide Survey (2003).

128. Id.

129. "Prior sex offenses" refers to those prior to the index offense. By definition, the index offense is that addressed at the individual's most recent court appearance. If, however, the individual was charged with, or convicted of, several offenses at that last court appearance, they do not count in the scoring. Only offenses prior to the latest court appearance count. In scoring the prior sex offenses, the Static-99 differentiated between charges and convictions. An individual received a score of $\mathrm{o}$ if he had no priors of any kind, a $\mathrm{I}$ if he had one to two charges or one conviction, a 2 if he had three to five charges or two to three convictions, and a 3 if he had six or more charges or four or more convictions. Hanson $\&$ Thornton, supra note 113 , at 20-21.

130. Prior sentencing dates require that the scorer total the number of prior occasions in which an individual appeared for a court for sentencing not including the index offense. Complete acquittals are not counted. If an individual has three or fewer prior sentencings, then he gets a score of $\mathrm{o}$. Four or more, he receives a I. Id. at 19-20.

131. This includes only convictions, so if an individual has reported engaging in such activity, it does not count. The conduct includes: exhibitionism, voyeurism, possession of obscene material, and engaging in obscene phone calls. If the individual has any convictions for such conduct, he receives a I; otherwise, he receives a 0 . Id. 
index nonsexual violence, ${ }^{132}$ prior nonsexual violence, ${ }^{133}$ any unrelated victims, ${ }^{134}$ any stranger victims, ${ }^{135}$ and any male $\cdot$ victims, ${ }^{136}$ young victims, ${ }^{137}$ and single victims. ${ }^{138}$ The Static-99 then translates the score into a risk rating: the higher the score, the higher the risk. ${ }^{139}$

\section{a. Predictive Accuracy of the Static-99}

Hanson and Thornton used four sample populations to test the accuracy of the Static-99. (These samples will be discussed in more detail in section II, below.) The first three were the same as had been used to create the RRASOR, excluding some minor modifications to correct coding errors and replace missing data. ${ }^{140}$ The Static- 99 was slightly more predictive then either of the original scales, and it showed moderate predictive accuracy. Hanson and Thornton reported that its predictive accuracy for sexual recidivism was $\mathrm{r}=0.33, \mathrm{ROC}$ area $=0.7 \mathrm{I},{ }^{141}$ and its predictive accuracy for

132. The scorer should only count the number of sexual convictions or charges before the index offense. If on the most recent court appearance, a person is charged with, or convicted of, more than one sexual offense- even if it is against more than one victim-he does not receive points for those other offenses. In effect, all of the charges or convictions handled on the same day count for scoring purposes as just the index offense. Id.

133. If the individual has convictions prior to the index offense for violence, then he receives a score of $\mathrm{I}$; if nor, he receives a score of $\mathrm{o}$. Id.

134. A person receives a score of $\mathrm{I}$ if the victim is unrelated. "A related victim is one where the relationship would be sufficiently close that marriage would normally be prohibited, such as parent, uncle, grand-parent, step-sister." Id. at 2 I.

135. A person receives a score of $\mathrm{I}$ if the victim was a stranger, meaning that he knew her for less than 24 hours. Id.

136. A person receives a score of $I$ if there are any sexual offenses involving boys except possession of child pornography. Id.

137. This required the score to consider the age of the individual at the time of the evaluation. If the individual was 25 or older, he receives a 0 ; anything younger, he received a I. Id. at 20-2I.

138. The individual received a score of 1 unless he had lived with a male or female lover or a spouse for at least two years. Id. at 21.

139. Id.

140. Id. at 5 .

141. Id. at 13. It is worth mentioning that an article by Sjostedt and Langstrom noted an unpublished study by Marnie Rice that found the ROC area of the RRASOR and the Static-99 as being at or just below 0.60 . If this ROC area were used, the number of false positives and false negatives would be higher. Gabrielle Sjosted \& Niklas Langstrom, Actuarial Assessment of Sex Offender Recidivism Risk: A Cross-Validation of the RRASOR and the Static-99 in Sweden, 25 Law \& Human Behav. 629-45, 630 (2001), 
violent (including sexual) recidivism was $r=0.32, \mathrm{ROC}$ area $=0.69 .^{142}$ Other researchers have confirmed these findings. Barbaree et al. evaluated the predictive accuracy of the Static-99 using a sample of 215 sex offenders and found a ROC area of 0.70 for both sexual and serious recidivism. ${ }^{143}$ Nunes et al. evaluated the predictive accuracy of the Static-99 on a sample of 258 adult sex offenders and found a ROC area of 0.70 for sexual recidivism and 0.65 for violent (including sexual) recidivism. ${ }^{144}$

Not all researchers have reported such high ROC values. Harris, Rice, et al. looked at the accuracy of the Static-99 in predicting sexual recidivism across four different samples of offenders and reported $\mathrm{ROC}$ values of $0.67,0.63,0.54$, and 0.62 , respectively. ${ }^{145}$ For violent recidivism, they reported ROC values of $0.66,0.67,0.60$, and $0.63 .{ }^{146}$ Harris, Rice, et al. also looked at the accuracy of the Static-99 in predicting sexual recidivism of child molesters (ROC area 0.65) and rapists (ROC area 0.59). ${ }^{147}$ Each of the samples had participants with missing data, meaning that they could not be scored on each of the Static-99 factors. When those participants were omitted so that only those with no missing data were considered, the ROC area increased. ${ }^{148}$

A ROC area of about 0.71 would indicate that the predictive ability of the instrument was significantly better than guessing for the groups as large as analyzed. As will soon be seen, however, even an improvement over a chance that is this large leaves the instrument grossly overpredicting the number of people who will reoffend.

It is important to explore the dimensions of predictive accuracy of the Static-99. To do so, we need to know the sensitivity-the proportion of people that the Static-99 accurately predicts will recidivate (true positives/number of

citing Dennis M. Doren, Recidivism Base Rates, Prediction of Sex Offender Recidivism, and the "Sexual Predator" Commitment Laws, 16 Behav. Sci. \& L. 97-114 (1998).

142. Hanson \& Thornton, supra note 113, at 13 .

143. Howard E. Barbaree, Michael C. Seto, Calvin M. Langton \& Edward J. Peacock, Evaluating the Predictive Accuracy of Six Risk Assessments Instruments for Adult Sex Offenders, 28(4) Crim. Just. \& Behav. 490, 512 (2001).

144. Kevin L. Nunes, Philip Firestone, John M. Bradford, David M. Greenberg \& Ian Broom, A Comparison of Modified Versions of the Static-99 and the Sex Offender Risk Appraisal Guide, 14 Sexual Abuse: J. Res. \& Treatment 253, 265 (2002).

I45. Harris, Rice, et al., supra note 120, at 419.

I46. Id.

I47. Id. at 420.

I48. Id. at $417-18$. 
people who will reoffend). We also need to know the specificity-the proportion of people that the Static-99 accurately predicts will not recidivate (true negatives/total number of people who will not reoffend). Since Hanson and Thornton do not reveal the sensitivity and specificity of the Static-99, these numbers will be conjectured.

One reasonable interpretation of the Static-99 is that sensitivity and specificity are equal, about 7I percent. The ROC area would also be consistent with a higher sensitivity and lower specificity or with a lower sensitivity and higher specificity (holding accuracy constant). It is not possible to raise both sensitivity and specificity without increasing accuracy. If Hanson and Thornton were most concerned with preventing the release of offenders who would in fact reoffend (false negatives), then they would want to increase the sensitivity of the instrument. In making this choice, they would have to increase the number of false positives-those the instrument would recommend against releasing who would not in fact reoffend. If instead Hanson and Thornton were most concerned with committing offenders who would not reoffend (false positives), then they would want to increase the specificity of the instrument. In making this choice, they would have to increase the number of false negatives. (See Appendix B for a detailed discussion of the predictive ramifications of using a different sensitivity or specificity.)

If equal sensitivity and specificity are assumed, given to individuals that the Static-99 predicts would reoffend, 7 predictions would be correct. Similarly, the Static-99 would be accurate for 7 of the ro predicted not to reoffend. Thus, a judge or jury that acted on the Static-99 predictions would confine 3 individuals who would not recidivate and ser free 3 individuals who would.

Sex Offenders. In a population of 1000 convicted sex offenders, the Department of Justice data discussed above estimates that 53 would recidivate and that 947 would not. Recidivism is defined as rearrest for a new sex crime within three years of release from prison. Assuming equal sensitivity and specificity, the Static-99 would correctly estimate that 38 of the 53 would recidivate (true positive) and falsely predict that 15 would not (false negative). It would also correctly predict that 672 of the 947 would not recidivate (true negative) and would falsely predict that 275 would recidivate (false positive). Thus it would recommend releasing is people who would recidivate and would recommend committing 275 people who would not. 
Table 2. Predictive accuracy of Static-99 as applied to DOJ data on sex offenders

\begin{tabular}{llcc}
\hline & & \multicolumn{2}{c}{ True outcome if all offenders were released } \\
\cline { 3 - 4 } & & Would recidivate & Would not recidivate \\
\hline Static-99 & Would recidivate & True positive & False positive \\
predicts & & $37.63=38$ & $274.63=275$ \\
& Would not recividate & False negative & True negative \\
& & $15.37=15$ & $672.37=672$ \\
\hline
\end{tabular}

At first glance, an accuracy of 7 I percent sounds quite high. Yet as shown above, when an instrument with this accuracy is applied to a population with a very low recidivism rate, it mistakenly predicts that many people would recidivate who would not. Referring to the first row of Table 2, the Static-99 would correctly predict that 38 sex offenders would recidivate, but it would incorrectly recommend the incarceration of 275 . Dividing the number of true positives by the number of total positives $(38 / 313)$ equals 0.I2; thus the Static-99 correctly predicts those sex offenders who would recidivate only $\mathrm{I} 2$ percent of the time.

Referring to the second row of Table 2, the Static-99 would falsely predict that is sex offenders would not recidivate, who in fact would. It would correctly identify 672 offenders as not recidivating. Dividing the number of true negatives by the number of total negatives $(672 / 687)$ equals 0.9782 ; thus the Static-99 would correctly predict those sex offenders who would not recidivate 98 percent of the time.

Since the belief that it is better to free ten guilty people than to punish one innocent has been a bedrock principle of the United States criminal justice system, it is worth looking at the ratio of false positives to true positives. Using the U.S. Department of Justice figures, the ratio between false positives (275) and true positives (38) is 7.24 to $\mathrm{I}$. That means that for every person that the Static-99 correctly predicts would recidivate, it would wrongly condemn 7 to continued incarceration. Of the 53 people who would in fact recidivate, the Static-99 misses 15 or 39 percent percent.

Child Molesters. The ratio of false positives to true positives is even more dramatic when child molesters are considered independently. The U.S. Department of Justice found that, of all child molesters released from fifteen states, 3.3 percent of those recidivated within three years. Recidivism is defined as being arrested for a new sex offense against a child within three years of release. Thus in a population of Iooo convicted child molesters, 
240 | NEW CRIMINAL LAW REVIEW | VOL. 14 | NO. 2 | SPRING 2011

Table 3. Predictive accuracy of Static-99 as applied to DOJ data on child molesters

\begin{tabular}{llcc}
\hline & \multicolumn{2}{c}{ True outcome if all offenders were released } \\
\cline { 3 - 4 } & & Would recidivate & Would not recidivate \\
\hline Static-99 & Would recidivate & True positive & False positive \\
predicts & & $23.43=23$ & $280.43=280$ \\
& Would not recividate & False negative & True negative \\
& & $9.57=10$ & $686.57=687$ \\
\hline
\end{tabular}

DOJ data estimates that 33 would recidivate and that 967 would not. The Static-99, however, would estimate that 23 of the 33 would recidivate (true positive) and falsely predict that to would not (false negative). It would also correctly predict that 687 of the 967 would not recidivate (true negative) and would falsely predict that 280 of the 967 would recidivate (false positive). Thus, if used for custodial commitment or continuation, the Static-99 would recommend releasing to people who would recidivate and would recommend committing 280 people to a locked mental facility who would not.

Referring to the Department of Justice figures in the first row of Table 3 , the Static- 99 would correctly predict that 23 child molesters would recidivate against a child. However, it would incorrectly recommend the incarceration of 280 . Dividing 23 by 303 equals 0.076 ; this means that the Static-99 would correctly predict which child molesters would recidivate only 8 percent of the time.

Referring to the second row of Table 3, the Static-99 would falsely predict that to child molesters would not recidivate who in fact would. It would correctly identify 687 child molesters as not recidivating. Dividing 687 by 697 equals 0.986 ; this means that the Static-99 would correctly predict which child molesters would not recidivate 99 percent of the time.

The ratio between false positives (280) and true positives (23) is 12.17 . Thus, for every child molester who the Static-99 correctly predicts would recidivate, it would condemn I2 people who would not. Of the 33 people who would recidivate, the Static-99 misses Io or 30 percent.

\section{b. Predictive Accuracy of Static-99 Using Recidivism}

Data with a Longer Follow-Up Period

The analysis above shows that even though the Static-99 prediction is better than random, it predicts many more false positives than true positives 
because so few sex offenders were rearrested for a new sex crime within three years of release from prison. Yet three years of data is an insufficient characterization of the recidivism over the lifetime of the released offender. What happens to the number of false positives when recidivism is estimated over a lifetime?

All available studies show that recidivism rates drop each year after an offender's release. "For all crimes (and almost all behaviors) the likelihood that the behavior will reappear decreases the longer the person has abstained from that behavior. The recidivism rate within the first two years after release from prison is much higher than the recidivism rate between years Io and 12 after release from prison." ${ }^{149}$ Harris and Hanson found that the rate of recidivism in the populations they studied was decreased by half every five years. ${ }^{150}$

A similar though steeper downward trend is evident in the U.S. Department of Justice data. According to the DOJ, sex offenders released in the United States were most likely to be arrested in the first year, and then the rate went down every subsequent year. Of the 513 sex offenders who were rearrested: 40 percent (205) were rearrested in the first year, 34 percent (174) in the second, and 26 percent (133) in the third. Of the 156 rapists who recidivated (i.e., were arrested for a new sex crime within three years of release): 40 percent (62) recidivated within the first year, 34 percent (53) in the second, and 26 percent (4i) in the third. With child molesters, the rates dropped even more quickly. Of the 219 child molesters who recidivated (i.e., were arrested for a new sex crime against a child within three years of release): 43 percent (94) were arrested in the first year, 33 percent (72) in the second, and 24 percent (53) in the third.

If this same downward trend were to continue, then the recidivism rate of sex offenders would reach in percent between ten and fifteen years after release from prison. (The number of additional rearrests would drop to a negligible level at that time.) Similarly, the recidivism rate of child molesters would reach 9 percent between ten and fifteen years after release from prison. (Again, the number of additional rearrests would drop to a negligible level at this time). See Appendix $C$ for a detailed discussion of these computations.

149. Andrew Harris \& Karl Hanson, Sex Offender Recidivism: A Simple Question, Public Safety and Emergency Preparedness Canada, 3 (2004).

I5o. Id. at II. 
Table 4. Predictive accuracy of Static-99 as applied to extrapolated DOJ data on sex offenders after release from prison (lifetime recidivism)

\begin{tabular}{llcc}
\hline & & True outcome if all offenders were released \\
\cline { 3 - 4 } & & Would recidivate & Would not recidivate \\
\hline Static-99 & Would recidivate & True positive & False positive \\
predicts & & $78.1=78$ & $258.1=258$ \\
& Would not recividate & False negative & True negative \\
& & $31.9=32$ & $631.9=632$ \\
\hline
\end{tabular}

Predictive Accuracy of Static-99 Using Extrapolated DOJ Recidivism Data. Using the extrapolated figures, I next calculated the predicted number of false positives and false negatives if the Static-99 is used to predict rearrest for a new sex crime during the lifetime of these offenders. I expected that II percent of sex offenders would recidivate, and so I estimated that out of 1000 offenders, no would recidivate and 890 would not. Since the Static-99 is $0.7 \mathrm{I}$ accurate, I multiplied $0.7 \mathrm{I}$ by 110 to calculate the number of offenders that the Static-99 would correctly predict to recidivate (true positive). That equaled 78.I or 78. I then subtracted 78.I from IIO to get 31.9 or 32. That means that the Static-99 would mistakenly predict 32 sex offenders would not recidivate, who in fact would (false negative).

To calculate the number of sex offenders the Static-99 would correctly predict to not recidivate (true negative), I multiplied the number predicted to not recidivate $(890)$ by 0.71 to get 631.9 or 632 . I then subtracted 631.9 from 890 to get the number the Static-99 would falsely predict to recidivate (false positive). This equaled 258.I or 258.

Even with a higher base rate of recidivism, the Static-99 still makes a lot of mistakes. Referring to the first row of Table 4, the Static-99 would correctly predict that 78 sex offenders would recidivate within their lifetime. However it would incorrectly recommend the incarceration of 258 . Dividing 78 by $336(78+258)$ equals 0.23 ; this means that the Static-99 would correctly predict those sex offenders who would recidivate within their lifetime only 23 percent of the time.

Referring to the second row of Table 4, the Static-99 would falsely predict that 32 sex offenders would not recidivate who in fact would. It would correctly identify 632 offenders as not recidivating. Dividing 632 by 664 $(32+632)$ equals 0.95 ; this means that the Static-99 would correctly predict those sex offenders who would not recidivate 95 percent of the time.

Using the extrapolated DOJ figures, the ratio between false positives (258) and true positives ( 78 is 3 to $\mathrm{I}$. This means that for every person that 
Table 5. Predictive accuracy of Static-99 as applied to extrapolated DOJ data on child molesters after release from prison (lifetime recidivism)

\begin{tabular}{llcc}
\hline & \multicolumn{2}{c}{ True outcome if all offenders were released } \\
\cline { 3 - 4 } & & Would recidivate & Would not recidivate \\
\hline Static-99 & Would recidivate & True positive & False positive \\
predicts & & $63.9=64$ & $263.9=264$ \\
& Would not recividate & False negative & True negative \\
& & $26.1=26$ & 646 \\
\hline
\end{tabular}

the Static-99 correctly predicts would recidivate over his lifetime, 3 others would be wrongly condemned to continued incarceration.

Child Molesters. Using the extrapolated figures, I next calculated the predicted number of false positives and false negatives if the Static-99 is used to predict recidivism during the lifetime of these child molesters. I expected that 9 percent of child molesters would recidivate, and so I estimated that out of Iooo offenders, 90 would recidivate and 910 would not. Since the Static-99 is 0.71 accurate, I multiplied $0.7 \mathrm{I}$ by 90 to calculate the number of offenders that the Static-99 would correctly predict to recidivate (true positive). That equaled 63.9 or 64 . I then subtracted 63.9 from 90 to get 26.I. That means that the Static-99 would mistakenly predict 26 sex offenders would not recidivate who in fact would (false negative).

To calculate the number of sex offenders the Static-99 would correctly predict to not recidivate (true negative), I multiplied the number predicted to not reoffend (910) by 0.7I to get 646.I or 64. I then subtracted 646.I from 9 Io to get the number the Static-99 would falsely predict to reoffend (false positive). This equaled 263.9 or 264 .

Even with a higher base rate of recidivism, the Static-99 still makes many mistakes. Referring to the extrapolated DOJ figures in the first row of Table 5, the Static-99 would correctly predict that 64 child molesters would be rearrested for a new sex crime against a child within their lifetime. However, it would incorrectly recommend the incarceration of 264. Dividing 64 by $328(64+264)$ equals 0.1951 . This means that the Static-99 would correctly predict those child molesters who would be rearrested for a new sex crime against a child only 20 percent of the time.

Referring to the second row of Table 5, the Static-99 would falsely predict that 26 child molesters would not be rearrested for a new sex crime against a child, who in fact would recidivate. It would correctly identify 646 child molesters as not recidivating. Dividing 646 by $676(26+646)$ 
equals 0.9556; this means that the Static-99 would correctly predict those child molesters who would not be rearrested for a new sex crime against a child 96 percent of the time.

Using the extrapolated DOJ figures, the ratio between false positives (264) and true positives (64) is 4 to $\mathrm{I}$. This means that for every child molester that the Static-99 correctly predicts would recidivate over his lifetime, it would wrongly condemn 4 to continued incarceration.

Exploring the Dimensions of Predictive Accuracy with a Significantly Higher Recidivism Rate-The Millbrook Study. It is clear that if the downtrend in the DOJ data continued so that the recidivism rate of sex offenders reached II percent and that of child molesters peaked at 9 percent, then the Static-99 would recommend the commitment of many who would not reoffend. Yet there is no way of knowing whether these trends would have continued because the follow-up period was only three years. Thus it is necessary to see how the Static-99 would perform if the recidivism rate was significantly higher.

Hanson, Scott, and Steffy studied the long-term recidivism of I9I child molesters released from the Millbrook Correctional Centre, a maximumsecurity, provincial correctional institution in Ontario, Canada. ${ }^{151}$ These men were released between 1965 and 1973, and the follow-up period was between fifteen and thirty years, with 63 percent of them followed for more then twenty years. Their recidivism rate; as defined by conviction for a new sex crime, was 35.I percent. ${ }^{152}$ Since Hanson et al. used conviction rather than rearrest rates, one may infer that the rearrest rates were even higher. Thus, this population appears to be markedly different from the DOJ population.

Child Molesters. In a population of rooo convicted sex offenders, the Millbrook study suggests that out of a population of 1000 child molesters, $35 \mathrm{I}$ would recidivate and 649 would not. Once again assuming equal sensitivity and specificity, the Static-99 would correctly estimate that 249.21 of the 351 would recidivate (true positive) and falsely predict that IOI.79 would not (false negative). It would also correctly predict that 672 of the 649 would not recidivate (true negative) and would falsely predict that

151. Hanson et al., supra note 54 , at 327.

152. Id. at 332. 
Table 6. Predictive accuracy of Static-99 as applied to Millbrook data on child molesters

\begin{tabular}{llcc}
\hline & & \multicolumn{2}{c}{ True outcome if all offenders were released } \\
\cline { 3 - 4 } & & Would recidivate & Would not recidivate \\
\hline Static-99 & Would recidivate & True positive & False positive \\
predicts & & $249.21=249$ & $188.21=188$ \\
& Would not recividate & False negative & True negative \\
& & $101.79=102$ & $460.79=461$ \\
\hline
\end{tabular}

I88.2I would recidivate (false positive). Thus it would recommend releasing 102 people who would recidivate and would recommend committing I88 people who would not.

Thus even if the recidivism rate is significantly higher, the Static-99 still makes many mistakes. Referring to the first row in Table 6, the Static-99 would correctly predict that 249 child molesters would recidivate, but it would incorrectly recommend the incarceration of 188 . Dividing the number of true positives by the number of total positives.(249.2I divided by 437.42) equals 0.5697; thus the Static-99 correctly predicts those child molesters who would recidivate only 57 percent of the time.

Referring to the second row in Table 6, the Static-99 would falsely predict that 102 sex offenders would not recidivate who in fact would. It would correctly identify $46 \mathrm{I}$ offenders as not recidivating. Dividing the number of true negatives by the number of total negatives ( 460.79 divided by 562.58) equals 0.8191 ; thus the Static-99 would correctly predict those sex offenders who would not recidivate 82 percent of the time.

Once again, it is worth looking at the ratio of false positives to true positives. Using the Millbrook figures, the ratio between false positives (I88.2I) and true positives (249.21) is 0.7552 to 1 . That means that for 3 child molesters that the Static-99 correctly predicts would recidivate, it would wrongly condemn I to continued incarceration. Of the 351 people who would in fact recidivate, the Static-99 misses 102 or 29 percent.

Reconciling the DOJ Study with the Millbrook Study: Which Recidivism Rate Should We Use? In sexually violent predator determinations, judges and juries are trying to determine the risk that a person previously convicted of a sex crime will reoffend if released. This determination is not being made within a spatial or temporal vacuum. The determination must be made about sex offenders who would be released into the United States, 
246 | NEW CRIMINAL LAW REVIEW | VOL. 14 | NO. 2 | SPRING 2011

Table 7. A Comparison of the Millbrook study with the DOS study on recidivism

\begin{tabular}{lll}
\hline & Sex offenders in DOJ Study & Sex offenders in Millbrook Study \\
\hline Sample size & 9,691 & 191 \\
Release date & 1994 & $1958-1974$ \\
Period of follow-up & 3 years & $16-30$ years \\
Definition of recidivism & Rearrest for a new sex crime & Conviction for a new sex crime \\
Finding & Sex offenders: $5.2 \%$ & All sex offenders: $35.1 \%$ \\
& Child Molesters: $3.2 \%$ & \\
Country & 15 states in the United & Ontario, Canada \\
& States & \\
Defining features & Diversity of different kinds & "Special sample." Many pri- \\
& of released sex offenders. & ors. Treatment for recurring \\
& Different crimes. Different & sexual desire. \\
& prior records. & \\
\hline
\end{tabular}

now, during the early part of the twenty-first century. Thus we must decide which study best reflects the recidivism rate of these offenders-that of the DOJ, Hanson et al.'s Millbrook study, or something in between.

Of course, there are some obvious differences between the two groups of sex offenders. The DOJ studied 9,69I sex offenders released from prison in 1994, and Hanson et al. studied 191 child molesters released from a maximum security correctional institute in Canada between 1958 and 1974. Although the DOJ study looked at all sex offenders released from fifteen different states, the Hanson study followed a group of child molesters that was unusual. Hanson et al. describe the Millbrook sample as follows: "The samples examined in this study were extreme groups. Many of the child molesters had prior convictions for sexual offenses, and most had been referred for treatment because of their persistent sexual problems."153

In addition, there have been significant changes in the last thirty-four to fifty years that distinguish the world into which the Millbrook offenders were released from that into which the DOJ offenders were released. For the purpose of predicting recidivism, the most relevant are those that have increased the control of released sex offenders as well as the consequences of reoffending. Some of these changes include: mandatory registration of sex offenders, increased penalty for sex offenses, special parole supervision for sex offenders, and federal reporting requirements for schools, hospitals, and day care providers if they suspect sexual abuse.

Taking all this into account, I contend that the Millbrook data should not be seen as representative of U.S. sex offenders released now. Thus I

153. Id. at 335 (emphasis added). 
would argue that the 35.I percent recidivism rate should be seen as high, and that one closer to the extrapolated DOJ data figures should be used. Even if the choice is made to use this higher recidivism rate, however, the incidence of false positives is still high.

Implications of a Higher Recidivism Rate. As the above discussion shows, the recidivism base rate has enormous implications for the kind of mistakes that the Static-99 and instruments like it will make. The lower the recidivism rate, the higher the chance that the Static-99 will recommend the commitment of someone who would not reoffend-a troubling out: come for a nation that values liberty. However, as Dennis Doren has pointed out, the higher the base rate of recidivism, the more likely it is that a person will be released who shouldn't be-a mistake that could have tragic implications for innocent men, women, and children. ${ }^{154}$

\section{c. Overstimating Risk}

Hanson and Thornton created the Static-99 by using data from four sample populations in Canada and Great Britain. These samples had significantly higher recidivism rates then samples of sex offenders in the United States, at least as determined by the 2003 U.S. Department of Justice study described above.

For instance, the first sample Hanson and Thornton used was from a maximum-security psychiatric facility, the Institut Philippe Pinel in Montreal, Canada. It included data on 344 sex offenders released between 1978 and 1993. On average, there were four years of follow-up and the recidivism rate (defined as convictions) was 15.4 percent. ${ }^{155}$ The second sample, from the Millbrook Correctional Centre discussed in detail above, was 35.I percent. ${ }^{156}$ The third sample was from a maximum-security psychiatric facility, the Oak Ridge Division of the Penetanguishene Mental Health Centre in Ontario, Canada. It contained data on 142 sex offenders referred to the program between 1972 and 1993. The sexual recidivism rate, defined as any charges or readmissions over ten years, was 35.I percent. ${ }^{157}$ The fourth sample contained follow-up information on 563 sexual offenders released from Her Majesty's

I54. Doren, supra note 141.

I55. Hanson \& Thornton, supra note 113 , at 5-7.

I56. Id.

I57. Id. 
Prison Service in England and Wales in 1979. The sexual recidivism rate, defined as convictions over sixteen years, was 25 percent.

These total recidivism rates are three to seven times higher then the rates found by the U.S. Department of Justice. ${ }^{158}$ The differences would have even been more extreme if the English and Canadian samples had measured recidivism by the number of rearrests, as was done in the DOJ study, instead of reconvictions, because many arrests do not result in conviction. The much higher recidivism rates make it appear that the samples used by Hanson and Thornton were biased upward.

Since these sample populations are used to predict the degree of risk posed by individuals from the United States being released now, it is imperative to determine whether this discrepancy can be justified. One possible explanation for the higher recidivism rates in the Hanson and Thornton sample populations is the longer follow-up period. The Pinel data contradicts this theory, however, since it found the recidivism rate (defined as conviction for a new sex crime within four years) to be 15.4 percent, three times higher then the DOJ study, which was also of three years and measured recidivism in terms of rearrest and not conviction.

Another explanation for the difference is the Hanson and Thornton sample populations are different than the sex offenders that the DOJ studied. Certainly two of the Hanson and Thornton samples, Pinel and Oak Ridge, seem different as they are both secure psychiatric facilities. As discussed in the previous section, Hanson has acknowledged that the child molesters studied in the Millbrook sample were an "extreme group."159

This is a very significant problem. Jurors in sexually violent predator cases are being asked to determine whether or not a person poses the risk of future dangerousness. In making its case, the state offers expert testimony that the individual in question has received a certain score on the Static-99, and that score places him with a group of offenders who recidivated at a certain rate-even though that rate of recidivism is significantly higher then that of American sex offenders. ${ }^{160}$

158. DOJ, supra note 28 .

159. Hanson et al., supra note 54 , at 335 .

160. Douglas Mossman makes a similar point in responding to a 2004 article by Dennis Doren. In that article, Doren concluded, "Although it may have been believed in the past that a sample's underlying recidivism base rate could affect the interpretation of the actuarial instruments' scores, that belief was found largely not supported. Within a relatively wide base rate range (i.e., a 12\% range within 5 years), the risk percentages essentially do not 
Table 8. Recidivism rates for Static-99 risk levelsa

\begin{tabular}{|c|c|c|c|c|c|c|c|}
\hline \multirow{2}{*}{$\begin{array}{l}\text { Static-99 } \\
\text { score }\end{array}$} & \multirow[b]{2}{*}{ Sample size } & \multicolumn{3}{|c|}{ Sexual recidivism } & \multicolumn{3}{|c|}{ Violent recidivism } \\
\hline & & 5 Years & 10 Years & 15 Years & 5 Years & 10 Years & 15 Years \\
\hline 0 & $107(10 \%)$ & 0.05 & 0.11 & 0.13 & 0.06 & 0.12 & 0.15 \\
\hline 1 & $150(14 \%)$ & 0.06 & 0.07 & 0.07 & 0.11 & 0.17 & 0.18 \\
\hline 2 & $204(19 \%)$ & 0.09 & 0.13 & 0.16 & 0.17 & 0.25 & 0.30 \\
\hline 3 & $190(18 \%)$ & 0.12 & 0.14 & 0.19 & 0.22 & 0.27 & 0.34 \\
\hline 4 & $100(9 \%)$ & 0.26 & 0.31 & 0.36 & 0.36 & 0.44 & 0.52 \\
\hline 5 & $129(12 \%)$ & 0.33 & 0.38 & 0.40 & 0.42 & 0.28 & 0.52 \\
\hline $6+$ & $129(12 \%)$ & 0.39 & 0.45 & 0.52 & 0.44 & 0.51 & 0.59 \\
\hline Average 3.2 & $1086(100 \%)$ & 0.18 & 0.22 & 0.26 & 0.25 & 0.32 & 0.37 \\
\hline
\end{tabular}

-Table from Hanson \& Thornton, supra note 113 , at 13.

For instance, referring to Table 8 , the individual might have scored a 4, which the state expert would say makes him akin to a group in which 26 percent recidivated within five years, $3 \mathrm{I}$ percent within ten years, and 36 percent within fifteen years. If that rate is biased upward, then it might be the case that a score of 4 is really associated with a significantly lower risk of recidivating. This problem exists even if the Static-99 has determined the relevant factors that predict future dangerousness. After all, jurors are being told not just that an individual is at risk of recidivating, but also that he is similar to people that recidivated at a particularly high rate. It is the power of this number and the fact that it is almost certainly biased upward that is troublesome.

Despite the fact that Karl Hanson is aware ${ }^{161}$ that the samples he used to create the Static- 99 have abnormally high recidivism rates as compared with the United States-he still recommends that these numbers be referred to

change. Even extreme base rate changes do not alter the interpretation of some actuarial scores (e.g., RRASOR $=4$ or 5). Doren, supra note 32, at 34. In his 2006 article, Mossman shows how variation in base rate can be a significant source of possible error in estimating the risk of sexual recidivism. He concludes, "Absent knowledge of the base rate of recidivism in the population from which an evaluee is drawn and the likelihood ratios associated with the instrument's score in that population, an evaluee's score on the RRASOR, and the TATIC-99, or other actuarial scales only represents a ranking of that evaluee's recidivism potential relative to other evaluees. Though it is reasonable to believe that the ranking abilities of a proven risk assessment scale will generalize to new populations in which the scale has not been tested, one should not translate a scale's scores into probabilities of recidivism without knowing how the scale functions in those new populations (that is, the likelihood rations associated with specific scores) and those populations' base rates of recidivism." Douglas Mossman, Another Look at Interpreting Risk Categories, i8 Sexual Abuse: J. Res. \& Treatment 4I-63 (2006).

161. Harris \& Hanson, supra note 149 , at 11. 
in court. In Hanson's most recent coding rules for the Static-99, he devotes an appendix to telling evaluators how they should communicate Static99-based risk information. It specifically advises evaluators to associate an individual's scores with the recidivism rates of the samples that he used to create the Static-99. ${ }^{162}$ At the very least, this advice might conflict with the ethical standards set forth by the American Psychological Association, which require psychologists to "take reasonable steps to prevent others from misusing information these techniques provides." ${ }^{163}$

\section{d. Problems with Coding Reliability}

When the Institute on Crime, Justice, and Corrections at George Washington University evaluated the Static-99 and RRASOR, they also looked at inter-rater reliability. They found that the only two items that exceeded 90 percent agreement were "any male victims" and "young (under 25)." 164 The degree of agreement on the other eight variables exceeded 80 percent. ${ }^{165}$ More problematic was the fact that raters only agreed on the final score 4I percent of the time, and they only agreed on the level of risk 73 percent of the time. ${ }^{166}$ The evaluators concluded, "The lack of reliability in the accessed risk level makes the validation of the instrument challenging because in 27 percent of the cases, the risk level of an [sic] prisoner is questionable as it is likely that another rater would have scored the prisoner differently, even if by only one level." 167

Hanson has recognized some of the coding problems, and in his revised instrument (Static-2002), he has proposed getting rid of one of the categories that caused the most confusion among raters. ${ }^{168}$ As will be discussed

162. Andrew Harris, Amy Phenix, R. Karl Hanson \& David Thornton, Static-99 Coding Rules Revised-2003, 7I.

163. Richard Rogers, The Uncritical Acceptance of Risk Assessment in Forensic Practice, 24(5) Law \& Human Behav. 595-605, 602 (2000).

164. James Austin, Johnette Peyton \& Kelly Dedel Johnson, Reliability and Validity Study of the Stati-99/RRASOR Sex Offender Risk Assessment Instruments, Final Report of the Institute on Crime, Justice and Corrections at the George Washington University, submitted to the Pennsylvania Probation and Parole, at s (Jan. 2003).

165. Id. at 5 .

I66. Id.

167 . Id. at 6 .

168. R. Karl Hanson, Notes on the Development of the Static 2002, 2003-Or, Publication of the Public Safety and Emergency Preparedness Canada, at 3. Hanson deleted "Ever lived with a lover for two years." 
in more detail below, the Static-2002 does not address the most significant shortcomings of the Static-99.

\section{e. Inaccuracy with Older Offenders}

A major problem with the Static-99 is that it overstates the recidivism risk of older offenders. In 2002, Hanson used data from ten follow-up studies of adult male sex offenders ages eighteen to over seventy (combined sample of 4,673$)$ to study the relationship between age and sexual recidivism. He found, "In the total sample, the recidivism rate declined steadily with age. . . . The association was linear." 169 Other researchers have come to similar results, ${ }^{170}$ even when analyzing the age effect on a sample of offenders with a higher recidivism rate than the general prison population. ${ }^{171}$

169. R. Karl Hanson, Recidivism and Age: Follow-Up Data from 4,673 Sexual Offenders, 17 J. Interpersonal Violence 1046, I053 (2002). Interestingly, Hanson found differences among offender groups. The recidivism rate of both incest offenders and rapists declined steadily over time, and neither type of offender released after age 60 recidivated. Although the recidivism rate of extra-familial child molesters also declined steadily with age, the drop was much less until the offender reached aged 49 , when recidivism dropped dramatically. Two extra-familial child molesters released after the age of 60 recidivated.

I70. Howard E. Barbaree, Calvin M. Langton, Ray Blanchard \& James M. Cantor, Aging Versus Stable Enduring Traits as Explanatory Constructs in Sex Offender Recidivism: Partitioning Actuarial Prediction into Conceptually Meaningful Components, 26 Crim. Just. \& Behav. 443 (2009); Patrick Lussier \& Jay Healey, Rediscovering Quetelet, Again: The "Aging" Offender and the Prediction of Reoffending in a Sample of Adult Sex Offenders, 26 Just. Q. 828-56 (2009); Patrick Lussier, Stacy Tzoumakis, Jesse Cale \& Joanna Ámirault, Criminal Trajectories of Adult Sex Offenders and the Age Effect: Examining the Dynamic Aspect of Offending in Adulthood, 20(2) Int'l Crim. Just. Rev. 147-68 (2010); Richard Wollert, Elliott Cramer, Jacqueline Waggoner, Alex Skelton \& James Vess, Recent Research $(\mathrm{N}=9,305)$ Underscores the Importance of Using Age-Stratified Actuarial Tables in Sex Offender Risk Assessments, 22 Sexual Abuse: J. Res. \& Treatment 471 (2010).

171. In 2007, Prentky and Lee looked at the age effect on a cohort of 136 rapists and II5 child molesters who had been civilly committed to a Massachusetts prison and were then followed for 25 years. They found that with rapists, recidivism dropped linearly as a function of age. With child molesters, however, they found that recidivism increased from age 20 to age 40, and then declined slightly at age 50 and significantly at age 6o. As Prentky and Lee point out, their sample is statistically small and comprised of offenders with a higher base rate of recidivism than drawn from the general prison population. "Although this latter consideration might be regarded as a limitation in terms of generalizability, it may also be seen as a strength of the study. Presumably, using a higher risk sample is a more severe test of the age-crime hypothesis; providing confirmatory support for the rapists and 'amplifying' or exaggerating the quadratic blip in Hansons' (2002) data for child molesters." Robert Alan 
Although the Static-99 tries to account for some of the decreased risk with advancing age, the adjustment is too small because it only looks at whether the individual is over or under twenty-five. It does not take into account that risk continues to drop as the person ages. As will be discussed below, Hanson and Thornton recognized this problem and attempted to correct it by revising age weights for the Static-99.

\section{Concluding Remarks on the Limited Promise of the New Penology}

The goal of the sexually violent predator laws is an understandable one-to prevent horrible crimes. The promise of the new penology is that this goal can be met by using objective and scientific actuarial instruments. As the above discussion shows, even the best of these instruments cannot meet this promise.

\section{A DUE PROCESS ANALYSIS OF THE STATIC-9g}

"The touchstone of due process is protection of the individual against arbitrary action of government." 172 In Hendricks, the Supreme Court held that because Kansas' Sexually Violent Predator law was civil, it did not violate the Constitution's ban on double jeopardy and ex post facto laws. Some scholars have criticized this decision, arguing that sexually violent predator laws impermissibly blur the line between civil commitments and punishment. They argue eloquently that civil commitments allow the state to do what the constitution prohibits: lock people away because the state believes they are dangerous. ${ }^{173}$

In this section, I will discuss two related problems with the Static-99. The first is the high likelihood that a person who would not reoffend is incorrectly predicted to do so. The second is the instrument's inability to link mental illness to future dangerousness. Each will be discussed in turn.

Prentky \& Austin F.S. Lee, Effect of Age-at-Release on Long Term Sexual Re-offense Rates in Civilly Committed Sexual Offenders, 19 Sexual Abuse: J. Res. \& Treatment 43 (2007).

172. Meachum v. Fano 427 U.S. 215 (1976) at 226, citing Dent v. West Virginia (1889) 129 U.S. $114,123$.

173. Janus, supra note 13 , at 5 . 


\section{A. Inaccuracy in Predicting Future Criminal Behavior}

In Kansas v. Hendricks, Justice Thomas referred to Schall v. Martin ${ }^{174}$ for the proposition that "from a legal point of view there is nothing unattainable about a prediction of future criminal conduct." ${ }^{175}$ Schall concerned the legality of Section 320.5(3)(b) of the New York Family Act, which authorized pretrial detention of juveniles if there was a finding of a "serious risk" that they would commit a crime before their return date to court. In upholding the New York statute, the Supreme Court dismissed a claim that it was "virtually impossible" to predict future criminal behavior accurately. It reached this conclusion despite the explicit finding to the contrary by the Court of Appeals as well as an amicus brief filed by the American Psychiatric Association, which rejected the idea that psychiatrists or psychologists could predict future criminal behavior, pointing out that as high as two out of three predictions of long-term future violence are wrong.

Previously, in Jurek $v$. Texas, seven justices rejected the claim that it was impossible to predict future behavior and that dangerousness was therefore an invalid consideration in imposing the death penalty. ${ }^{176}$ Later, in Barefoot v. Estelle, the Court rejected the argument that "psychiatrists, individually and as a group, are incompetent to predict with an acceptable degree of reliability that a particular criminal will commit other crimes in the future and so represents a danger to the community." 177 In so doing, it noted the testimony of Dr. John Monahan, who "concluded that 'the best clinical research currently in existence indicates that psychiatrists and psychologists are accurate in no more than one out of three predictions of violent behavior over a several-year period among institutionalized populations that had both committed violence in the past... and who were mentally ill."'178 The Court held instead that the evidence should be admitted, and the jury could decide what weight to give it. ${ }^{179}$

174. Schall v. Martin (1984) 467 U.S. 253.

175. Kansas v. Hendricks, supra note 33 , at 358.

176. 428 U.S. 262 (1976).

177. Barefoot v. Estelle, 463 U.S. 880 (1983) at 896.

178. Id. at 9or.

179. "The differences in opinion go to the weight [of the evidence] and not the admissibility of such testimony. ... Such disputes are within the province of the jury to resolve. Indeed, it is a fundamental premise of our entire system of criminal jurisprudence that the purpose of the jury is to sort out the true testimony from the false, the important matters, and, when called upon to do so, to give greater credence to one party's expert witnesses than 
At first blush it seems that the Supreme Court would reject a due process challenge to the admissibility of the Static-99 and instruments like it-even if the justices knew of the instruments' serious limitations. Yet on further analysis, the problems with accurate prediction in the sexually violent predator context should be distinguished from problems in the context of pretrial detention in Schall or deciding on the appropriate level of punishment in Jurek $v$. Texas and Barefoot v. Estelle.

The liberty interest at stake in sexually violent predator cases is radically different from that in Schall. Schall concerned pretrial detention only, and the Court emphasized in its opinion that the period of detention could not last longer then seventeen days. ${ }^{180}$ The sexually violent predator laws, in contrast, concern a potential lifetime commitment to a locked facility.

Jurek v. Texas and Barefoot v. Estelle can also be distinguished because the prediction of future danger is only one factor among many that was used in deciding whether an individual should get the death penalty. Not only must the defendant have been convicted of one of a few enumerated serious homicides, but also the jurors must consider his mental state at the time of the homicide and the presence of any mitigating circumstances related to his background, character, and crime. ${ }^{181}$ Since future dangerousness caused by mental illness is the only lawful justification for the sexually violent predator laws, it is an insurmountable problem if the state is incapable of proving future danger with a high degree of accuracy.

As explained above, the number and type of mistakes that the Static-99 makes depends on the recidivism rate of the underlying population. If the extrapolated DOJ data is correct, then the Static-99 recommends the commitment of too many people who would not recidivate, thus constituting an "arbitrary action of government" 182 and a due process violation. If the underlying recidivism rate is much higher, like that of the Millbrook study, then the instrument makes fewer Type I errors (false positives) and so is significantly less problematic from a due process perspective. Even with the higher recidivism rate, however, it is still necessary to ask what conduct the

another's." Id at 902. This followed the holding in Estelle v. Smith in which the Court held that the jury should receive all relevant information and was "in no sense disapproving the use of psychiatric testimony bearing on future dangerousness." 45I U.S. 454 (198I).

I8o. Schall v. Martin, supra note 174 , at 271 .

I8I. Sumner v. Shuman (1987) 483 U.S. 66.

182. Meachum v. Fano (1976). 427 U.S. 215 (1976) at 226, citing Dent v. West Virginia (1889) 129 U.S. I14, 123. 
potential SVPs are at risk of repeating. If it is not in fact sexual and violent, then the commitments are still troublesome.

\section{B. Inability to Link Mental Illness to Future Dangerousness}

In Foucha v. Louisiana, ${ }^{183}$ the Supreme Court held that to confine an individual, future dangerousness is not enough; he must also be mentally ill. Leroy Hendricks cited Foucha in his argument that Kansas's Sexually Violent Predator statute violated his substantive due process rights because a "mental abnormality" as defined by the Kansas legislature did not constitute mental illness. Justice Thomas disagreed, stating, "the term 'mental illness' is devoid of talismanic significance." ${ }^{84}$ Thomas pointed out in his majority opinion that there was wide disagreement in the medical community as to what constitutes mental illness. "These disagreements, however, do not tie the State's hands in setting the bounds of its civil commitment laws. In fact, it is precisely where such disagreement exists that legislatures have been afforded the widest latitude in drafting such statutes." 185

Regardless of the terminology used, the state still must prove that an individual has some cognitive or emotional problems so that it can separate the civil commitment enterprise from the criminal proceedings and avoid naked double-jeopardy style punishment. More onerous still, the state must prove that this mental illness causes the individual to have a difficult time controlling himself, thus making him a danger to the public. In upholding the Kansas statute, Justice Thomas wrote, "The statute thus requires proof of more than a mere predisposition to violence; rather, it requires evidence of past sexually violent behavior and a present mental condition that creates $a$ likelihood of such conduct in the future if the person is not incapacitated." 186 Although the Court upheld the SVP laws in Hendricks, it did so only by setting a very specific requirement: For the SVP laws to be constitutional, the state must prove not only that a person has a current mental abnormality but also that this mental abnormality causes him to be at risk of reoffending sexually. As will be shown, the Static-99 by its very design is incapable of making this causal link.

183. Foucha v. Louisiana (1992) 504 U.S. 71.

184. Kansas v. Hendricks, supra note 33, at 359.

185. Id. at 360 .

I86. Id. at 357 (emphasis added). 


\section{What is a Mental Abnormality or Mental Disorder?}

When most people think of mental illness, they think of diseases like schizophrenia or bipolar disorder. According to a task force of the American Psychiatric Association, although most sex offenders have some sort of personality disorder, most do not have any major psychiatric disorders. ${ }^{187}$ Instead, the mental abnormality most often referred to in justifying a person's civil commitment under the sexually violent predator laws is the presence of a paraphilia.

The American Psychiatric Association's Diagnostic and Statistical Manual of Mental Disorders (DSM-IV) describes a paraphilia as the presence of:

Recurrent, intense, sexually arousing fantasies, sexual urges, or behaviors generally involving (I) nonhuman objècts, (2) the suffering or humiliation of oneself or one's partner, or (3) children or other nonconsenting persons that occur over a period of at least six months (Criterion A). For some individuals, paraphilic fantasies or stimuli are obligatory for erotic arousal and are always included in sexual activity. In other cases, the paraphilic preferences occur only episodically (e.g., perhaps during periods of stress), whereas at other times the person is able to function sexually without paraphilic fantasies or stimuli. The behavior, sexual urges or fantasies cause clinically significant distress or impairment in social, occupational, or other important areas of functioning (Criterion B). ${ }^{188}$

DSM-IV stresses the distinction between the "nonpathological" use of fantasies or objects for sexual titillation. "Fantasies, behaviors, or objects are paraphilic only when they lead to clinically significant distress or impairment (e.g., are obligatory, result in sexual dysfunction, require participation of nonconsenting, lead to legal complications, or interfere with social relationships)." ${ }^{189}$ Examples of paraphilias include pedophilia, exhibitionism, voyeurism, sexual sadism, and frotteurism. Some experts believe that a small subset of rapists suffer from paraphilic coercive disorder, who are described as "individuals with intense, repetitive urges of 6 months' duration to commit rape, who had either acted on these urges or were disturbed by

187. American Psychiarric Association, Dangerous Sex Offenders: A Task Force Report, at 7 (2005).

188. Id. at 6, quoting American Psychiatric Association, Diagnostic and Statistical Manual of Mental Disorders, 4th Ed., 522-23 (1994).

I89. Id. at 6, citing American Psychiatric Association, at 525. 
their presence." 190 This disorder has never been included in the Diagnostic and Statistical Manual of Mental Disorders, but it is a proposed revision to the DSM V. ${ }^{191}$

Although the presence of a paraphilia is linked to sexual offending, not all sex offenders actually suffer from a paraphilia. According to a task force of the American Psychiatric Association, "Only the paraphilic diagnoses focus directly on psychopathological features of deviant sexual behavior, but these conditions appear to be absent in most offenders. In contrast, a significant number of sex offenders may have substance abuse or personality disorder diagnoses, but these conditions usually have little explanatory connection to the offender's sexual behavior." ${ }^{192}$

\section{Static-99's Inability to Take into Account Mental Abnormality}

Karl Hanson, one of the creators of the Static-99, acknowledges that it does not measure sexual deviance. ${ }^{193}$ This is in part because the instrument evaluates mostly unchanging historical and demographic factors; it does not take into account factors that do change with time and experience, such as how an individual is doing in treatment. The factors that it does consider are almost completely unrelated to any sort of mental illness.

\section{Static vs. Dynamic Factors}

One of the comments that defense attorneys make about the Static-99 is that a person would get the same score after he had died-and was certain not to reoffend. This means that facts such as how an individual is doing in treatment, whether his mental disorder has abated or gotten worse, or whether he states a desire to reoffend are not taken into account in the Static-99 score.

Hanson has recognized the deficiencies with using only static factors and has specifically called for more research into the dynamic factors associated with recidivism. ${ }^{194}$ Dynamic risk factors predict recidivism, but unlike static factors, they are susceptible to change. ${ }^{195}$ Examples of dynamic risk factors include deviant sexual preferences and substance abuse. ${ }^{196}$

190. Id. at 6.

19I. Id. http://www.dsm5.org/ProposedRevisions/Pages/proposedrevision.aspx?rid=416.

192. Id. at 9 .

193. Hanson, supra note 96, at 66.

194. Id. at 50.

I95. Id.

I96. Id. at 51. 
One of the goals of treatment is to try to address these factors to lower the risk of reoffense: Yet if a person is doing well in treatment, his Static-99 score will not change. Other dynamic factors associated with lowering aggressive behavior include religious convictions, social relations, self-esteem, and acceptance by parents. ${ }^{197}$ The Static-99, however, fails to take into account any dynamic factors, and as Hanson points out, "the consequence is that there is much more evidence to justify committing offenders than there is for releasing them." 198

Hanson has acknowledged that this deficiency undermines the usefulness of the Static-99: "The authors of Static-99, however, have never claimed that it provides a complete and comprehensive assessment of sexual recidivism risk. Because it addresses only static, historical factors, Static-99 does not directly measure the enduring psychological traits that are presumed to motivate sexual offending." 199

Douglas Badger, a sexually violent predator in California, provides an excellent example of this deficiency. Although Mr. Badger completed his inpatient sex offender program, and his treatment team recommended that he be released, his Static-99 score remained the same. In addition, Mr. Badger showed no signs of any sexual deviance while at Atascadero State Hospital. He never demonstrated any inappropriate or predatory behavior despite the fact that he was surrounded at Atascadero by patients who fit his victim profile. ${ }^{200}$ Still his score did not change.

Mr. Badger was given the antiandrogen drug Lupon but was taken off of it in 2003 after suffering the side effect of osteoporosis. Despite not having been on the drug for over two years, Mr. Badger's testosterone level remained at I00, significantly lower then the average level 200-600 (adjusted for age)..$^{201}$ Again, no change was reflected in his score. Mr. Badger testified that he had no sexual urges at all: "I had thoughț, but I didn't have a sexual urge. (The men in the jail) were good-looking, but I didn't have a sexual urge. I didn't

197. Rogers, supra note 163 , at 598 , citing R. Plutchik, Outward and Inward Directed Aggressiveness: The Interaction between Violence and Suicidality, 28 Pharmacopsychiatry 47-57 (1995, Supplement).

198. Hanson, supra note 96 , at 51 .

199. Hanson, supra note 126 , at 2.

200. Reporter's Transcript of Court Trial of People of the State of California v. Douglas Badger, County of San Diego, at 68.

201. Id. at 26, and author's conversation with Badger's trial attorney, San Diego County Public Defender Richard Gates on Jan. 4, 2006. 
have an erection or feel anything sexually. They were just handsome." ${ }^{202}$ Yet none of this information-not his success in treatment, his lack of recent deviant behavior, his low testosterone level, or his lack of desire for sex-none of it affected his Static-99 score or his predicted risk of reoffending.

Scholars like Hannah-Moffat have questioned the "pessimistic theoretical accounts of risk in criminal justice associated with the 'new penology' and 'actuarial justice." ${ }^{203}$ Instead, Hannah-Moffat points to a more recent generation of actuarial instruments that were "designed to identify areas for intervention in order to reduce and not simply contain risk." ${ }^{204}$ In treating the risk subject as "transformative," the instruments support a rehabilitative instead of punitive agenda. Unfortunately, as the above discussion shows, the Static-99 is not part of this more hopeful generation.

\section{No Attempt to Measure Sexual Deviance or Mental Illness}

Karl Hanson has acknowledged that the Static-99 does not measure sexual deviance, the relevant mental illness for the purpose of sexual recidivism, ${ }^{205}$ nor was it intended to measure other types of mental illness. ${ }^{206}$

The Static-99 calls for researchers to score an individual on a number of factors. It does not require, nor even suggest, that the individual be interviewed. ${ }^{207}$ The higher an individual's score, the higher is his risk of recidivism. Clearly, the Static-99 is intended to provide a quantitative measure, although not of sexual deviance. A plain reading of the eight factors below (summarized in Table 9) makes it clear that the instrument does not directly address any form of mental illness codified by the American Psychiatric Association.

The first factor is whether the individual has been charged or convicted of any prior sexual offenses. Acquittals at trial are counted, as are charges

202. Id. at 135 .

203. Kelly Hannah-Moffat, Criminogenic Needs and the Transformative Risk Subject: Hybridizations of Risk/Need in Penality, in Punishment and Society 29, 30 (2005).

204. Kelly Hannah-Moffat, Assembling Risk and the Restructuring of Penal Control, 46 Brit. J. Criminology 438, 449 (2006).

205. Hanson, supra note 96 , at 66 .

206. The coding rules for the Static-99 begin by describing the nature of the instruments: "The Static-99 utilizes only static (unchangeable) factors that have been seen in the literature to correlate with sexual reconviction in adult males. The estimates of sexual and violent recidivism produced by the STATIC-99 can be thought of as a baseline for risk for violent and sexual reconviction." Harris, Phenix, et al., supra note 162, at 3. Thus there is not even a pretense that the instrument is designed to measure sexual deviance or mental illness.

207. Id. 
260 | NEW CRIMINAL LAW REVIEW | VOL. 14 | NO. 2 | SPRING 2011

Table 9. Relevance of Static-99 factors tó sexual deviance and mental illness

\begin{tabular}{lcc}
\hline Static-99 factors & $\begin{array}{c}\text { Measures current } \\
\text { sexual deviance }\end{array}$ & $\begin{array}{c}\text { Measures current } \\
\text { mental illness }\end{array}$ \\
\hline 1. Prior sex offenses & No & No \\
2. Prior sentencing dates & No & No \\
3. Convictions for nonsexual violence & No & No \\
4. Prior nonsexual violence & No & No \\
5. Any stranger victims & No & No \\
6. Any male victims & No & No \\
7. Youth (age 18-25) & No & No \\
8. Single (ever lived with lover for at & No & No \\
least two years) & & \\
\hline
\end{tabular}

of consensual staturory rape, sex with a prostitute, and urinating in public. ${ }^{208}$ Although sexual intercourse between two teenagers or sex with a prostitute may not be a good idea, it is not an indication of mental illness. The Static-99 would classify a nineteen-year-old male who had consensual sex with a sixteen-year-old female or a man who had sex with a prostitute as more likely to molest a child in the future, other factors held constant. Similarly, an individual accused of child molestation who was acquitted by a jury would forever be judged more likely to molest a child, even if exculpatory evidence was introduced at trial, such as mismatched DNA.

Even if an offender was convicted of child molestation, he may still not be mentally ill. Much more information about the underlying offense than merely the fact of the conviction is needed to conclude that the individual has a mental illness. As mentioned above, many sex offenders do not suffer from a paraphilia.

The second factor, prior sentencing dates, indicates past criminal activity, not mental illness. Certainly some criminals are mentally ill, just as some people who are not criminals are mentally ill. Modern psychiatry does not link criminal behavior directly to mental illness.

The third factor, any convictions for noncontact sex offenses, is a broad category that includes possession of child pornography, peeping, and exhibitionism. The latter is classified as a paraphilia in the DSM-IV. However, once again, the Static-99 is overly broad, lumping together behavior that is not related to mental illness with behavior that may be.

The fourth factor, nonsexual violence in the index offense, may not be related to sexual deviance or mental illness.

208. Id. at 15,18 . 
The fifth factor, whether the person has any stranger victims, is not directly related to sexual deviance or mental illness. It may be correlared with recidivism but it is not a sign of mental illness.

Similarly, unless homosexuality is considered an indication of sexual deviance (the DSM-IV does not classify it as such), then factor six, whether there were any male victims, is also unrelated to sexual deviance or mental illness.

The last two factors-whether the perpetrator is young and whether he has lived with a lover for at least two years-are also not directly related to sexual deviance or mental illness.

\section{Possible Solution: Using Unaccounted-for Dynamic Factors to}

\section{Adjust a Person's Static-99 Score}

Some proponents of actuarial instruments like the Static-99 have suggested using clinical factors to adjust a person's score. Although Karl Hanson notes the "poor track record of clinical prediction," he states "some form of adjusted actuarial risk assessment can be expected to represent the highest standard of practice in the coming years." ${ }^{209}$ The factors that he advocates using are those that have been correlated with recidivism-such as sexual deviance and antisocial lifestyle - but are not factors considered in the Static-99. ${ }^{210}$

The problem with this solution is that it undermines what is supposed to be the strength of the actuarial instrument-its objectivity. There are no current guidelines regarding which factors matter and how they should be weighted, and so those determinations, albeit by experts, would be subjective. Furthermore, no research has been conducted that shows either the accuracy or the validity of the adjusted approach. ${ }^{211}$ As one researcher noted, "adjusted actuarial assessments rely on (i) methods that are trivially correlated with recidivism (clinical judgment) (ii) to identify factors that bear a small correlation with recidivism, (iii) in order to adjust actuarial estimates that are moderately correlated with recidivism. This procedure obviously creates ample opportunities for error. Adjusted actuarial assessment can therefore be defined as an un-standardized, inconsistently applied, ad hoc procedure."212

209. Hanson, supra note 96 , at 50,67 .

210. Id. at 66.

211. Shoba Sreenivasas, Linda E. Weinberger \& Thomas Garrick, Expert Testimony in Sexually Violent Predator Commitments: Conceptualizing Legal Standards of "Mental Disorder" and "Likely to Reoffend," 3 I J. Am. Acad. Psychiatry \& L. 47I-85, 480 (2003).

212. Terence W. Campbell, Sex Offenders and Actuarial Risk Assessments: Ethical Considerations, 21 Behav. Sci. \& L. 269-79, 275 (2003). 


\section{Concluding Remarks on the Static-99}

The Static-99 does not take mental illness into account when predicting whether an individual is likely to reoffend, and this omission cannot be fixed by using factors that a clinician thinks are relevant to adjust the score. The structural inability of the Static-99 to account for mental illness is constitutionally significant because without showing a causal link between an individual's mental illness and his risk of future offense, the Static-99 does not meet the criteria set forth in Foucha v. Louisiana ${ }^{213}$ or Kansas v. Hendricks. ${ }^{214}$ As a result, using the Static-99 to justify civil commitment under the sexually violent predator laws violates an individual's substantive due process rights.

\section{WILL A DIFFERENT INSTRUMENT KEEP THE PROMISE OF THE NEW PENOLOGY?}

Turning to another currently available actuarial instrument will not solve the problems associated with the Static-99. As mentioned earlier, the instruments most commonly used are the Rapid Risk Assessment for Sexual Offense Recidivism (RRASOR), ${ }^{215}$ the Structured Anchored Clinical Judgment (SACJ), ${ }^{216}$ the Sex Offender Risk Appraisal Guide (SORAG), and the Minnesota Sex Offender Screening Tool-Revised (MnSOST-R). ${ }^{217}$ Although it is not yet ready to be used as anything other then a research measurement, ${ }^{218}$ Hanson and Thornton have recently developed the Static2002. ${ }^{219}$ In addition, Hanson and Thornton have revised the Static-99 (Static-99R) to better take into account age in assessing risk. ${ }^{220}$ Each instrument will be addressed briefly regarding its accuracy and its ability to measure mental illness.

213. Foucha v. Louisiana, supra note 183.

214. Kansas v. Hendricks, supra note 33.

215. Hanson, supra note 96.

216. Grubin, supra note IIO; Janus, supra note 13.

217. Epperson et al., supra note II2.

218. Calvin M. Langton, Howard E. Barbaree, Kevin T. Hansen, Leigh Harkins \& Edward J. Peacock, Reliability and Validity of the Static-2002 among Adult Sexual Offenders with Reference to Treatment Status, 34 Crim. Just. \& Behav. 616, 638 (2007).

219. Hanson, supra note 168 .

220. Leslie Helmus, Kelly M. Babchisin, R. Karl Hanson \& David Thornton, Static-99R: Revised Age Weights, Oct. 5, 2009. 


\section{A. Inaccuracy}

Both the RRASOR and the SACJ are less accurate then the Static-99. The ROC area of the RRASOR is 0.68 , and the ROC area is of the SACJ is $0.67 .{ }^{221}$ This means that the ratio of false positives to true positives will be even higher than it is with the Static-99, thus constituting even more of a constitutional due process problem.

Although the SORAG was more accurate than the Static-99 (ROC $0.73),{ }^{222}$ it was still only moderately predictive, which will also lead to a high ratio of false positives to true positives.

The MnSOST-R is widely used by behavioral scientists in civil commitment procedures for sex offenders. ${ }^{223}$ This is because it offers six-year predictions ranging from a o to an 88 percent chance that the person will reoffend ${ }^{224}$ Although the developers of the MnSOST-R reported that it had a high degree of accuracy, ${ }^{225}$ these results were not replicated by peerreviewed studies. ${ }^{226}$

Furthermore, when the MnSOST-R was evaluated from a cross-validational perspective, ${ }^{227}$ results showed that the original risk predictions were greatly inflated. Risk estimates using the MnSOST-R were compared with those of the RRASOR and the Static-99, and the difference was startling: on the same population, MnSOST-R predictions for future reoffense averaged about 75 percent, as contrasted with the about 35 percent for other instruments. ${ }^{228}$ "These considerations suggest that predictions based on the MnSOST-R may have unnecessarily placed the freedom of many individuals in jeopardy." ${ }_{229}$

221. Hanson \& Thornton, supra note II3, at 8.

222. Sjostedt $\&$ Langstrom, supra note I22, at 25-40.

223. Richard Wollert, The Importance of Cross-Validation in Actuarial Test Construction: Shrinkage in the Risk Estimates for the Minnesota Sex Offender Screening Tool-Revised, 2(I) J. Threat Assessment 89, 94 (2002).

224. Id. at 94.

225. Epperson et al., supra note 112.

226. See Barbaree et al., supra note 143, at 490-521, and Darci L. Bartosh, Tina Garby, Deborah Lewis, \&c Steve Gray, Differences in the Predictive Validity of Actuarial Risk Assessments in Relation to Sex Offender Type, 47 Int'l J. Offender Therapy \& Comp. Criminology 422-38 (2003).

227 . Wollert, supra note 223 , at $89,96$.

228. Id.

229. Id. 
Hanson and Thornton's attempts at making the Static-2002 more accurate than the Static-99 did not succeed. Although the Static-2002 was more accurate at predicting violent recidivism, there was no marked improvement in its ability to predict sexual recidivism. ${ }^{230}$ The Static-2002 did show less variability across samples than the Static-99. 231 As mentioned previously, the Static-2002 is still at the experimental stage and is not ready to be used in SVP proceedings. ${ }^{232}$

As discussed earlier in this paper, the Static-99 does not adequately take into account the relationship between an offender's advancing age and his lowered risk of recidivism. Helmus et al. recognized this problem, and in 2009, they created a revised version of the Static-99 (Static-99R). ${ }^{233}$ The Static-99R used a new age weighting that scored an offender between I point and -3 points based on his age. ${ }^{234}$ This modification slightly increased the predictive accuracy of the Static-99R; The ROC now ranges from 0.7I to 0.72 .235

Thus all of the instruments have similar deficiencies with regards to accuracy. Not surprisingly, some commentators have questioned what the motive is in using these actuarial tables in civil commitment proceedings: "We must consider whether there may be a political bias to overestimate the degree of accurate prediction achieved in order to justify keeping some offenders imprisoned. In other words, are these actuarial scales being misused by some who have already made up their minds to keep an offender incarcerated for crimes they have not yet committed." ${ }^{236}$.

230. Calvin M. Langton, Howard E. Barbaree, Michael C. Seto, Edward J. Peacock, Leigh Harkins \& Kevin T. Hansen, Actuarial Assessment of Risk for Reoffense among Adult Sex Offenders: Evaluating the Predictive Accuracy of the Static-2002 and Five Other Instruments, ${ }_{34}$ Crim. Just. \& Behav. 37, 40 (2007).

23I. Id. at 40 .

232. Langton et al., supra note 218 .

233. Helmus et al., supra note 220.

234. Wollert et al. contend that the Static-99R does not adequately account for the relationship between age and recidivism. As a result, it still overstates the risk of recidivism. Instead, Wollert et al. argue that "age-stratified" experience tables are a better method for taking age into account. Wollert et al., supra note 170 .

235. Id. at 6 .

236. Thomas Grisso (Moderator), Neil M. Malamuth, Howard Barbaree, Vernon Quinsey \& Raymond Knight Discussants, Comments by Dr. Malamuth, Risk Assessment: Discussion of the Section, 989 Ann. N.Y. Acad. Sci. 236, 238 (2003). 


\section{B. Relationship to Mental IIIness}

Like the Static-99, the RRASOR, the Static-2002, and the Static-99R consider only static factors that have been associated with reoffending and do not measure mental illness. ${ }^{237}$

The SACJ-Min and the SORAG, in contrast, look at static historical factors as well as factors like deviant sexual arousal and psychopathy. ${ }^{238} \mathrm{With}$ the SACJ-Min, if two or more of these additional factors are present, the individual's level of risk is increased. Thus an individual's mental illness (at least as defined by paraphilia) may play a role in assessing that person's risk of reoffending. ${ }^{239}$ In assessing an individual's risk, the SORAG takes into account whether the person has ever met DSM-III criteria for personality or schizophrenia, as well as a person's score on the Hare psychopathy test and whether they've have ever registered any deviant interest on phallometric testing. ${ }^{240}$ Although the SACJ-Min and the SORAG consider aspects of an individual's mental health, they still do not pass the constitutional hurdle set forth in Hendricks because an expert could not testify that the risk of future dangerousness was caused by the individual's mental illness rather than other unrelated factors.

\section{The APA Task Force's Assessment of Sexually Violent Predator Legislation}

The American Psychiatric Association created a task force to evaluate the sexually violent predator laws; in 2005 they published their findings. After reviewing the laws as well as the science behind the notion of the sexually violent predator, the task force concluded that sexually violent predator laws are bad for the offender and psychiatry in general:

In the opinion of the Task Force, sexual predaror commitment laws represent a serious assault on the integrity of psychiatry, particularly with regard to

237. R. Karl Hanson \& David Thornton, Improving Risk Assessment for Sex Offenders: A Comparison of Three Actuarial Scales, 24 Law \& Human Behav. 119, 20 (2000); Harris, Phenix, et al., supra note I62. Hanson, supra note 168 . As mentioned earlier, the Static-99 and the Static-99R take age into account, which is not a static factor.

238. David Thornton, Ruth Mann, Steve Webster, Linda Blud, Rosie Travers, Caroline Friendship \& Matt Erikson, Distinguishing and Combining Risks for Sexual and Violent Recidivism, 989 Ann. N.Y. Acad. Sci. 225-35, 225-26 (2003).

239. Hanson \& Thornton, supra note 237 , at 121 .

240. Harris, Rice, et al., supra note 120 , at 415. 
defining mental illness and the clinical conditions for compulsory treatment. Moreover, by bending civil commitment to serve essentially nonmedical purposes, sexual predator commitment statutes threaten to undermine the legitimacy of the medical model of commitment. In the opinion of the Task Force, psychiatry must vigorously oppose these statures in order to preserve the moral authority of the profession and to ensure continuing societal confidence in the medical model of civil commitment. ${ }^{241}$

\section{CONCLUSION}

Stories about dangerous sex offenders pervade the media and the public consciousness. These stories lead many to believe that sex offenders are monsters incapable of controlling themselves who will continue to prey on innocent women and children unless they are locked away forever. The reality, however, is quite different. The U.S. Department of Justice statistics show that recidivism rates in the United States are low, which means that many sex offenders can and do control themselves. Even those committed as predators are not, according to then-clinical director of Minnesota's sexual predator program, "a totally different breed of human being. ... The difference is a little more [criminal] history for those committed, or a little more violence." ${ }^{242}$ Indeed, as the discussion above shows, those committed as sexually violent predators may not be that different after all. No state requires that a person facing commitment as a sexually violent predator have more than one qualifying conviction, and that conviction may not even need to be sexual or violent.

Yet high-profile offenders like Earl Shriner in Washington convince people that sex offenders are different. Citizens understandably demand protection from such horrific though rare acts of brutality, and legislatures have responded by including far too many in what would be appropriate punishment for the Earl Shriners of the world. Since it is unconstitutional to punish someone twice for the same crime, the SVP laws are premised on the grounds that they are civil. The state is locking up individuals who have a diagnosed mental abnormality that causes them to have difficulty controlling themselves such that they pose the risk of committing future sexually violent crimes. To prove that a person is dangerous, the state uses instruments like the Static-99.

24I. Id. at 173.

242. Janus, supra note 13 , at 41 
Just as the SVP laws hide the real intentions of the legislators, so do the actuarial instruments mask the state's inability to predict future risk accurately. Although instruments like the Static-99 may appear to be scientifically accurate, they make many mistakes. As the above analysis shows, for every Iooo people evaluated, the instrument would recommend the release of between Io and 102 who would reoffend, and it would recommend the commitment of between 188 and 280 who would not. Both outcomes pose a serious problem to the state's legitimacy. If the state releases people who end up reoffending, cirizens will become angry and disillusioned because they were not adequately protected. If the state commits people who would not reoffend, it sacrifices core values of liberty and dignity.

Some might respond that although these mistakes are regrettable, they do not constitute a fatal flaw. After all, we make predictions every day in the criminal justice system, and we do so knowing that we will often get it wrong. Although it is true that predictions are commonly used, they are qualitatively different in the SVP arena. In pretrial hearings, for instance, the application for bail is influenced by predictions of future danger; however, the cost of a mistake is limited because of the defendant's constitutional right to a speedy trial. In an SVP hearing, by contrast, the cost of a mistaken prediction is significantly greater because the person can be locked away forever.

In sentencing and parole hearings, a prediction of future danger influences what punishment a person will receive from among a set of alternatives that is directly related to what the person was convicted of doing. Thus in an important sense, the person deserves the punishment that he receives. In contrast, predictions of future danger are used in SVP hearings to decide whether or not a person should continue to be detained after he has completed his criminal sentence. Since the Constitution states that he cannot be punished twice, the only grounds for committing him is that he is mentally ill and dangerous. Since the whole architecture of SVP commitments rests on whether a person is dangerous, it is critical that we be able to predict dangerousness accurately.

In addition, the instrument's inability to link mental illness to danger undermines the constitutional protections promised by the Supreme Court in Hendricks and Crane. In Hendricks, the Court sought to distinguish the sexually violent predator laws from preventative detention laws by requiring that an individual have a currently diagnosed mental disorder 
that causes him to have difficulty controlling himself. ${ }^{243} \mathrm{~A}$ finding of future dangerousness on its own would have been insufficient to meet this constitutional requirement. ${ }^{244}$ Later in Crane, the Court sought to define mental - disorder in such a way that it would "distinguish the dangerous sexual offender whose serious mental illness, abnormality, or disorder subjects him to civil commitment from the dangerous but typical recidivist convicted in an ordinary case." Yet as the prior analysis shows, the Static-99 does not even purport to take into account an individual's mental illness in assessing his risk of recidivism, thus undermining the constitutional limitations set forth in Hendricks and Crane.

But even if a more accurate instrument could be devised, it might still pose problems from a constitutional perspective. Both the Fifth and the Fourteenth Amendments of the Constitution protect against deprivation of life, liberty, or property without due process of law. Yet in their very construction, actuarial instruments like the Static-99 undermine this protection. Rather than being provided with due process of law, a prospective SVP is evaluated on the basis of historical characteristics that predict recidivism in other populations. These characteristics don't include any rehabilitation that the individual has subsequently undergone, any treatment he has completed, or any physical changes that might have occurred such as aging, voluntary chemical castration, or even paralysis. Thus, other than getting older, there is nothing the individual can do to change his score on the Static-99.

Not only do the sexually violent predator laws undermine basic values and protections, but also they do so at an enormous monetary price. Because they demand tremendous financial resources to operate, they divert funds from addressing the lion's share of sex crimes that are perpetrated by family and friends. They also strip money away from parole, probation, ${ }^{245}$ and sex offender treatment programs that have been shown to reduce recidivism by as much as 30 to 40 percent. ${ }^{246}$ Given that state

243. Kansas v. Hendricks, supra note 33.

244. Id.

245. Arizona developed an intensive probation program for sex offenders deemed particularly dangerous. Research shows that it has been effective at lowering recidivism. See La Fond, supra note 12 , at $494-95$. .

246. Id. at 116-26. Levenson \& D'Amora, supra note 35, reviewed the various studies of the efficacy of sex offender treatment and found that "although the research is not 
budgets are limited, spending more money on confining SVPs means that resources are not available for other social programs like education and health care.

In a world of limited resources, states spend hundreds of millions of dollars locking up individuals for crimes that they might commit instead of spending money solving crimes that have already happened. This irony is especially poignant with regard to the thousands of rape kits that languish in police departments across the country. According to a 2009 Human Rights Watch report, in Los Angeles alone, there are at least 12,669 untested sexual assault kits. ${ }^{247}$ To test these kits, Los Angeles would need to hire additional staff in their DNA laboratory at a cost of approximately $\$ \mathbf{I} .6$ million per year. ${ }^{248}$ Although the Los Angeles Police Department has made some progress in reducing the number of unanalyzed kits, the California budget crisis has led to mandatory work furloughs that have slowed down these efforts. ${ }^{249}$ Consequently, thousands of rapists are walking the streets, potentially stalking new victims.

It is time to rethink sexually violent predator legislation. The hundreds of millions of dollars that we devote every year to confine a few thousand people would be better spent on solving crimes that have actually happened and on preventing the sex crimes that are most common--those inflicted by friends and intimates.

What is at stake goes beyond money and the lives of a few thousand people. By confining people without due process, the SVP laws erode our constitutional regard for liberty. They play on our deepest fears, and in so doing tell us that it is acceptable to treat human beings as if they are monsters. In the process, the SVP laws destroy two of the fundamental underpinnings of democracy: equality and respect.

unequivocal, there is evidence to believe that treatment can be helpful for many sex offenders." Id. at 179. But see Harris, Rice, et al., supra note 120 , at 421 , who found that sex offender treatment was nonsignificantly associated with increased recidivism.

247. Human Rights Watch, Testing Justice (Mar. 31, 2009).

248. Id.

249. LAPD Cuts Backlog of Untested DNS Cases in Half, Los Angeles Times, Oct. 5 , 2009, http://latimesblogs.latimes.com/lanow/2009/ro/lapd-cuts-backlog-of-untested-dnacases-in-half-.html. 
Appendix A. U.S. Department of Justice data on recidivism of sex offenders released in 1994 from 15 states (recidivism tracked over 3 full years)

\begin{tabular}{|c|c|c|c|c|c|c|}
\hline & Rapists & $\begin{array}{c}\text { Sexual } \\
\text { assaulters }\end{array}$ & $\begin{array}{c}\text { Child } \\
\text { molesters }\end{array}$ & $\begin{array}{l}\text { Statutory } \\
\text { rapists }\end{array}$ & $\begin{array}{l}\text { Total sex } \\
\text { offenders }\end{array}$ & $\begin{array}{l}\text { Non-sex } \\
\text { offenders }\end{array}$ \\
\hline Number released & 3,115 & 6,576 & 4,295 & 443 & 9,691 & 262,420 \\
\hline $\begin{array}{l}\text { Number rearrested for } \\
\text { any new sex offense }\end{array}$ & 155 & 362 & 221 & 22 & 517 & 3,328 \\
\hline $\begin{array}{l}\text { Percentage rearrested } \\
\text { for any new sex offense }\end{array}$ & $5.0 \%$ & $5.5 \%$ & $5.1 \%$ & $5.0 \%$ & $5.3 \%$ & $1.3 \%$ \\
\hline $\begin{array}{l}\text { Number convicted for } \\
\text { any new sex offense }\end{array}$ & 100 & 243 & 150 & 16 & 339 & \\
\hline $\begin{array}{l}\text { Percentage convicted for } \\
\text { any new sex offense }\end{array}$ & $3.2 \%$ & $3.7 \%$ & $3.5 \%$ & $3.6 \%$ & $3.5 \%$ & \\
\hline \multicolumn{7}{|c|}{ Breakdown of rearrest for any sex crime per year atter release from prison } \\
\hline First year & $2.0 \%$ & $2.2 \%$ & $2.2 \%$ & $2.0 \%$ & $2.1 \%$ & \\
\hline Second year & $3.7 \%$ & $4.1 \%$ & $3.9 \%$ & $3.2 \%$ & $3.9 \%$ & \\
\hline Third year & $5.0 \%$ & $5.5 \%$ & $5.1 \%$ & $5.0 \%$ & $5.3 \%$ & \\
\hline $\begin{array}{l}\text { Percentage rearrested for } \\
\text { sex crime against child }\end{array}$ & $1.4 \%$ & $2.5 \%$ & $3.3 \%$ & $2.5 \%$ & $2.2 \%$ & $<0.5 \%$ \\
\hline $\begin{array}{l}\text { Number rearrested for } \\
\text { any new crime }\end{array}$ & 1,432 & 2,731 & 1,693 & 221 & 4,163 & 179,391 \\
\hline $\begin{array}{l}\text { Percentage rearrested } \\
\text { for any new crime }\end{array}$ & $46.0 \%$ & $41.5 \%$ & $39.4 \%$ & $49.9 \%$ & $43.0 \%$ & $68 \%$ \\
\hline
\end{tabular}

\section{Appendix B. Predictive Implications of Using}

Maximum Sensitivity or Specificity

In the previous discussion, I assumed equal sensitivity and specificity. Since these affected the $2 \times 2$ matrices described above, I will now repeat these calculations by assuming maximum sensitivity and specificity. I will not change the $7 \mathrm{I}$ percent accuracy because it is not a conjectured number but rather that reported by the developers of the Static-99.

\section{Department of Justice Study: Sex Offenders}

I will begin by increasing the sensitivity of the instrument-i.e., the instrument's accuracy in detecting those who will recidivate-to the maximum, which is 100 percent. In a population of 1000 convicted sex offenders, the U.S. Department of Justice data discussed in Chapter $3^{250}$ estimates that 53 would recidivate and that 947 would not. Assuming a sensitivity of 100 percent, the Static- 99 would correctly estimate that $\$ 3$ of the 53 would recidivate 250. DOJ, supra note 28 , at 18 . 
Table 10. Predictive accuracy of Static-99 as applied to DOJ data on sex offenders (accuracy $=71 \%$; sensitivity $=100 \%$; specificity $=69 \%$ )

\begin{tabular}{llcc}
\hline & & \multicolumn{2}{c}{ True outcome if all offenders were released } \\
\cline { 3 - 4 } & & Would recidivate & Would not recidivate \\
\hline Static-99 & Would recidivate & True positive & False positive \\
predicts & & 53 & 290 \\
& Would not recividate & False negative & True negative \\
& & 0 & 657 \\
\hline
\end{tabular}

(true positive) and falsely predict that o would not (false negative). Because the accuracy is set at 71 percent, the sum of the true positives and true negatives is 710 . Because the number of true positives is 53 , the number of true negatives is $657(710-53)$. Thus the Static-99 would also correctly predict that 657 of the 947 would not recidivate (true negative) and would falsely predict that 290 would recidivate (false positive). This is a specificity of 69.38 or 69 percent $(947 \times 0.6938=657)$.

Thus with a sensitivity of roo percent, the Static-99 would recommend releasing o people who would recidivate and would recommend committing 290 people who would not. This is a ratio of false positives to true positives of $5.47=5.5$ to $\mathrm{I}$. Thus for every person who would recidivate, the Static-99 would recommend committing 5.5 who would not.

What happens if I increase the specificity of the instrument-i.e., its accuracy in predicting those who will not recidivate? Because the accuracy of the instrument is 71 percent, the number of true negatives plus the number of false positives must equal $7 \mathrm{ro}$. If we set the number of true positives at $O$, the maximum number of true negatives is 710 . Thus the highest specificity possible is 74.97 or 75 percent $(947 \times 0.7497=710)$.

In a population of 1000 convicted sex offenders, the U.S. Department of Justice data discussed in Chapter $3^{251}$ estimates that 53 would recidivate and that 947 would not. Assuming specificity of 75 percent, the Static-99 would incorrectly estimate that $O$ of the 53 would recidivate (true positive) and that 53 would not (false negative). This is a sensitivity of o percent. It would also correctly predict that 710 of the 947 would not recidivate (true negative) and would falsely predict that 237 would recidivate (false positive).

Thus, assuming the maximum specificity of 75 percent, the Static-99 would recommend releasing 53 people who would recidivate and would recommend committing 237 people who would not.

251. Id. 
272 | NEW CRIMINAL LAW REVIEW | VOL. 14 | NO. 2 | SPRING 2011

Table 11. Predictive accuracy of Static-99 as applied to DOJ data on sex offenders (accuracy $=71 \%$; specificity $=75 \%$; sensitivity $=0 \%$ )

\begin{tabular}{llcc}
\hline & & \multicolumn{2}{c}{ True outcome if all offenders were released } \\
\cline { 3 - 4 } & & Would recidivate & Would not recidivate \\
\hline Static-99 & Would recidivate & True positive & False positive \\
predicts & & 0 & 237 \\
& Would not recividate & False negative & True negative \\
& & 53 & 710 \\
\hline
\end{tabular}

2. Department of Justice Study: Child Molesters

Assuming a sensitivity of Ioo percent, I will now look at the predictive implications of using the Static-99 on the child molestation data. The U.S. Department of Justice found that of all child molesters released from fifteen states, 3.3 percent recidivated against a child within three years. Thus in a population of rooo convicted child molesters, the DOJ data estimates that 33 would recidivate and that 967 would not. Assuming sensitivity of Ioo percent, the Static-99 would estimate that 33 of the 33 would recidivate (true positive) and falsely predict that o would not (false negative). It would also correctly predict that 677 of the 967 would not recidivate (true negative) and would falsely predict that 290 of the 967 would recidivate (false positive). This is a specificity of 70.01 or 70 percent.

Thus if it used for custodial commitment or continuation, with a sensitivity of 100 percent, the Static-99 would recommend releasing o people who would recidivate and would recommend committing 290 people to a locked mental facility who would not. This is a ratio of false positives to true positives of 8.79 to I. Thus for every person the Static-99 correctly predicts will recidivate against a child within three years, it incorrectly recommends that 9 be committed to a locked mental hospital for an indeterminate amount of time.

Table 12. Predictive accuracy of Static-99 as applied to DOJ data on child molesters (accuracy $=\mathbf{7 1} \%$; sensitivity $=100 \%$; specificity $=70 \%$ )

\begin{tabular}{llcc}
\hline & \multicolumn{2}{c}{ True outcome if all offenders were released } \\
\cline { 3 - 4 } & Would recidivate & Would not recidivate \\
\hline Static-99 & Would recidivate & True positive & False positive \\
predicts & Would not recividate & False negative & True negative \\
& & 0 & 677 \\
\hline
\end{tabular}


Table 13. Predictive accuracy of Static-99 as applied to DOJ data on child molesters (accuracy $=71 \%$; specificity $=73 \%$; sensitivity $=0 \%$ )

\begin{tabular}{llcc}
\hline & & \multicolumn{2}{c}{ True outcome if all offenders were released } \\
\cline { 3 - 4 } & & Would recidivate & Would not recidivate \\
\hline Static-99 & Would recidivate & True positive & False positive \\
predicts & & 0 & 257 \\
& Would not recividate & False negative & True negative \\
& & 33 & 710 \\
\hline
\end{tabular}

What happens if I increase the specificity of the instrument-i.e., the instrument's accuracy in predicting those who will not recidivate? Because the accuracy of the instrument is 7I percent, the number of true negatives plus the number of false positives must equal 710 . If we set the number of true positives at $\mathrm{O}$, the maximum number of true negatives is $7 \mathrm{IO}$. Assuming a recidivism rate of 3.3 percent, we know that the number of false positives plus the number of true negatives equals 967 . Because 710 is 73.4 percent of 967 , we know that the highest specificity possible is 73.4 or 73 percent.

In a population of 1000 convicted child molesters, the DOJ data discussed in Chapter $3^{252}$ estimates that 33 would recidivate against a child and that 967 would not. Assuming an accuracy of $7 \mathrm{I}$ percent and a specificity of 73 percent, the Static-99 would falsely predict that 33 would not recidivate who would (false negative). This is a sensitivity of o percent. It would also correctly predict that 710 of the 967 would not recidivate (true negative) and would falsely predict that 257 would recidivate (false positive). Thus it would recommend releasing 33 people who would recidivate and would recommend committing 257 people who would not.

\section{Extrapolated DOJ Recidivism Data: Sex Offenders}

In evaluating the predictive accuracy of the Static-99 on the extrapolated recidivism data, I will begin by increasing the sensitivity of the instrumenti.e., the instrument's accuracy in detecting those who will recidivate-to the maximum, which is roo percent. In a population of rooo convicted sex offenders, the extrapolated DOJ data estimates that no would recidivate and that 890 would not. Assuming sensitivity of Ioo percent, the Static-99 would correctly estimate that IIo of the IIo would recidivate (true positive) and falsely predict that o would not (false negative). Because the accuracy 
Table 14. Predictive accuracy of Static-99 as applied to extrapolated DOJ data on sex offenders (accuracy $=71 \%$; sensitivity $=100 \%$; specificity $=67 \%$ )

\begin{tabular}{lccc}
\hline & & \multicolumn{2}{c}{ True outcome if all offenders were released } \\
\cline { 3 - 4 } & & Would recidivate & Would not recidivate \\
\hline Static-99 & Would recidivate & True positive & False positive \\
predicts & & 110 & 290 \\
& Would not recividate & False negative & True negative \\
& & 0 & 600 \\
\hline
\end{tabular}

is set at $7 \mathrm{I}$ percent, the sum of the true positives and true negatives is 7IO. Because the number of true positives is IIO, the number of true negatives is 600 (710-110). Thus the Static-99 would also correctly predict that 600 of the 890 would not recidivate (true negative) and would falsely predict that 290 would recidivate (false positive). This is a specificity of 67.41 or 67 percent. Thus it would recommend releasing o people who would recidivate and would recommend committing 290 people who would not. This is a ratio of false positives to true positives of 290 to 110 or 2.6 to I. Thus for every I sex offender who the Static-99 correctly predicts would recidivate within his lifetime, it commits 3 who would not.

What happens if I increase the specificity of the instrument-i.e., the instrument's accuracy in predicting those who will not recidivate? Because the accuracy of the instrument is 71 percent, the number of true negatives plus the number of false positives must equal 7IO. If we set the number of true positives at 0 , the maximum number of true negatives is 710 . Thus the highest specificity possible is 74.97 or 75 percent $(947 \times 0.749=710)$.

In a population of 1000 convicted sex offenders, the extrapolated DOJ data estimates that IIo would recidivate and that 890 would not. Assuming specificity of 75 percent and sensitivity of o percent, the Static-99 would correctly estimate o of the IIo who would recidivate (true positive) and would falsely predict that no would not (false negative). This is a sensitivity of o percent. It would also correctly predict that 710 of the 890 would not

Table 15. Predictive accuracy of Static-99 as applied to DOJ data on sex offenders (accuracy $=71 \%$; specificity $=75 \%$; sensitivity $=0 \%$ )

\begin{tabular}{llcc}
\hline & & \multicolumn{2}{c}{ True outcome if all offenders were released } \\
\cline { 2 - 4 } & Would recidivate & Would not recidivate \\
\hline $\begin{array}{l}\text { Static-99 } \\
\text { predicts }\end{array}$ & Would recidivate & True positive & False positive \\
& Would not recividate & False negative & True negative \\
& & 110 & 710 \\
\hline
\end{tabular}


Table 16. Predictive accuracy of Static-99 as applied to DOJ data on child molesters (accuracy $=71 \%$; sensitivity $=100 \%$; specificity $=68 \%$ )

\begin{tabular}{llcc}
\hline & & \multicolumn{2}{c}{ True outcome if all offenders were released } \\
\cline { 3 - 4 } & & Would recidivate & Would not recidivate \\
\hline Static-99 & Would recidivate & True positive & False positive \\
predicts & & 90 & 290 \\
& Would not recividate & False negative & True negative \\
& & 0 & 620 \\
\hline
\end{tabular}

recidivate (true negative) and would falsely predict that 170 would recidivate (false positive). Thus it would recommend releasing no people who would recidivate and would recommend committing 180 people who would not.

\section{Extrapolated DOJ Recidivism Data: Child Molesters}

I will begin by increasing the sensitivity of the instrument-i.e., the instrument's accuracy in detecting those who will recidivate-to the maximum, which is 100 percent. In a population of rooo convicted child molesters, the extrapolated DOJ data estimates that 90 would recidivate against a child and that 910 would not. Assuming a sensitivity of Ioo percent, the Static-99 would correctly estimate that 90 of the 90 would recidivate (true positive) and falsely predict that o would not (false negative). Because the accuracy is set at $7 \mathrm{I}$ percent, the sum of the true positives and true negatives is 710 . Because the number of true positives is 90, the number of true negatives is $620(710-90)$. Thus the Static-99 would also correctly predict that 620 of the 910 would not recidivate (true negative) and would falsely predict that 290 would recidivate (false positive). This is a specificity of 68.13 or 68 percent. Thus it would recommend releasing o people who would recidivate and would recommend commirting 290 people who would not. This is a ratio of false positives to true positives of 290 to 90 or 3.2 to I. Thus for every child molester the Static-99 correctly predicts would recidivate, it incorrectly predicts 3 who would not.

Table 17. Predictive accuracy of Static-99 as applied to DOJ data on child molesters (accuracy $=71 \%$; specificity $=78 \%$; sensitivity $=0 \%$ )

\begin{tabular}{lccc}
\hline & \multicolumn{2}{c}{ True outcome if all offenders were released } \\
\cline { 3 - 4 } & & Would recidivate & Would not recidivate \\
\hline Static-99 & Would recidivate & True positive & False positive \\
predicts & & 0 & 200 \\
& Would not recividate & False negative & True negative \\
& & 90 & 710 \\
\hline
\end{tabular}


Table 18. Predictive accuracy of Static-99 as applied to Millbrook data on child molesters (accuracy $=71 \%$; sensitivity $=100 \%$, specificity $=55 \%$ )

\begin{tabular}{llcc}
\hline & & \multicolumn{2}{c}{ True outcome if all offenders were released } \\
\cline { 3 - 4 } & & Would recidivate & Would not recidivate \\
\hline Static-99 & Would recidivate & True positive & False positive \\
predicts & & 351 & 290 \\
& Would not recividate & False negative & True negative \\
& & 0 & 359 \\
\hline
\end{tabular}

What happens if I increase the specificity of the instrument-i.e., the instrument's accuracy in predicting those who would not recidivate? Because the accuracy of the instrument is 71 percent, the number of true negatives plus the number of false positives must equal 710 . If we set the number of true positives at 0 , the maximum number of true negatives is 710 . Thus the highest specificity possible is 78.02 or 78 percent $(910 \times 0.78=710)$.

In a population of 1000 convicted child molesters, the extrapolated DOJ data estimates that 90 would recidivate against a child and that 910 would not. Assuming a specificity of 78 percent and a sensitivity of o percent, the Static-99 would correctly estimate o of the 90 who would recidivate (true positive) and would falsely predict that 90 would not (false negative). This is a sensitivity of o percent. It would also correctly predict that 710 of the 890 would not recidivate (true negative) and would falsely predict that 200 would recidivate (false positive). Thus it would recommend releasing 90 people who would recidivate and would recommend committing 200 people who would not.

5. Exploring the Dimensions of Predictive Accuracy with a Significantly Higher Recidivism Rate-The Millbrook Study

Of a population of Iooo convicted sex offenders, the Millbrook study would suggest that 351 would recidivate and 649 would not. Once again assuming maximum sensitivity of 100 percent, the Static-99 would correctly estimate that 351 of the 35I would recidivate (true positive) and that o would not (false negative). It would also correctly predict that 359 of the 649 would not recidivate (true negative) and would falsely predict that 290 would recidivate (false positive). Thus it would recommend releasing o people who would recidivate and would recommend committing 290 people who would not. The ratio of false positives to true positives is $35 \mathrm{I}$ to 290 or I to 0.826 . Thus for every I person the Static-99 correctly predicts would recidivate, 0.826 would not. 


\section{Appendix C. Extrapolating DOJ Recidivism Data into the Future}

Assuming that the downward trend seen in the DOJ data continues at the same rate, it is possible to estimate recidivism rates into the future.

\section{Extrapolated Recidivism Rates for Sex Offenders}

The first step required estimating the drop in sex offender recidivism per year. To do this, I calculated the percentage drop in sex offenders who were rearrested for a new sex crime between year I and year 2, yielding 15 Percent $(205-174=31 ; 3 I / 205=0.1512=15$ percent $)$. I then calculated the drop between year 2 and year 3 , yielding 24 percent $(174-133=41 ; 41 / 174=$ $0.2356=24$ percent). I acknowledge that this is not a perfect method; by all accounts three years' worth of data is inadequate to predict ten, fifteen, and twenty years into the future with any accuracy. Yet because the DOJ provided only three years of data, I had no other choice.

To calculate the predicted drop between year 3 and year 4 and further through year 20, 1 averaged the decreases between year 1 and year 2 and between year 2 and year 3 . This yielded 19 percent $(0.1512+0.2356=0.3868$; $0.3868 / 2=0.1934=19$ percent). It should be noted that $\mathrm{I} 9$ percent is a conservative estimate because the data shows that the recidivism rate was in fact decreasing over time. These calculations also show that Hanson's finding, that sex offender recidivism dropped by 50 percent over five years, is not borne out by the DOJ data. Sex offender recidivism dropped by 39 percent in three years; if that trend continued, it would drop by half in less than four years.

I then used 19 percent to calculate the number of sex offenders recidivating through year 20. Specifically, I calculated the total who recidivated in year 3 (133) and multiplied it by 0.19 to get the difference in the number I expected would be rearrested for a new sex crime in year 4 (25.27). I then subtracted that number from year 3 to get the estimated number who would be rearrested for a new sex crime in year 4 and rounded it up (133-25.27= $107.73=108)$. I then repeated this process for each of the subsequent years by starting with the estimated number (not rounded up) who would recidivate for year $X$, multiplying that number by 0.19 , and then subtracting that number from year $X$ to get the number $I$ expected would be rearrested for a new sex crime in year $X+I$. Table 19 shows the results.

This analysis shows that after year 15 , recidivism remained almost unchanged. The numbers drop so much that even extrapolating Ioo years into the future, recidivism is not expected to exceed in percent. Thus this table 
Table 19. Extrapolated sex offender recidivism rates based on DOJ data extrapolated for years 4-20 after release from prison (recidivism is defined as rearrest for a new sex crime)

\begin{tabular}{|c|c|c|c|c|}
\hline Year & $\begin{array}{l}\text { Total predicted to } \\
\text { recidivate }\end{array}$ & $\begin{array}{l}\text { Percent of total sex } \\
\text { offenders }\end{array}$ & $\begin{array}{l}\text { Numerical drop } \\
\text { between year and } \\
\text { preceding year }\end{array}$ & $\begin{array}{c}\text { Percentage } \\
\text { drop between } \\
\text { year and } \\
\text { previous year }\end{array}$ \\
\hline 1 & 205 (actual data) & $0.02115=2.11 \%$ & $\mathrm{n} / \mathrm{a}$ & $\mathrm{n} / \mathrm{a}$ \\
\hline 2 & 174 (actual data) & $0.0179=1.79 \%$ & 31 & $15 \%$ \\
\hline 3 & 133 (actual data) & $0.0137=1.37 \%$ & 41 & $24 \%$ \\
\hline 4 & $107.73=108$ & & $25.27=25$ & $19 \%$ \\
\hline 5 & $\begin{array}{l}87.2613=87 \\
\text { Total predicted to } \\
\text { recidivate within } \\
5 \text { years }= \\
706.9913= \\
707\end{array}$ & $\begin{array}{c}706.9913 / 9691= \\
0.0730=7 \%\end{array}$ & $20.4687=20$ & $19 \%$ \\
\hline 6 & $70.4204=70$ & & $16.5796=17$ & $19 \%$ \\
\hline 7 & $57.0405=57$ & & $13.3799=13$ & $19 \%$ \\
\hline 8 & $46.2028=46$ & & $10.8377=11$ & $19 \%$ \\
\hline 9 & $37.4243=37$ & & $8.7785=9$ & $19 \%$ \\
\hline 10 & $\begin{array}{l}30.3137=30 \\
\text { Total predicted to } \\
\text { recidivate within } \\
10 \text { years }= \\
948.3928= \\
948\end{array}$ & $\begin{array}{c}948.3928 / 9691= \\
\cdot 0.0979=10 \%\end{array}$ & $7.1106=7$ & $19 \%$ \\
\hline 11 & $24.5541=25$ & & $5.7596=6$ & $19 \%$ \\
\hline 12 & $19.8888=20$ & & $4.6653=5$ & $19 \%$ \\
\hline 13 & $16.1099=16$ & & $3.7789=4$ & $19 \%$ \\
\hline 14 & $13.0490=13$ & & $3.0609=3$ & $19 \%$ \\
\hline 15 & $\begin{array}{l}10.5697172=11 \\
\text { Total predicted to } \\
\text { recidivate within } \\
15 \text { years }= \\
1032.5644= \\
1033\end{array}$ & $\begin{array}{c}1032.5644 / 9691= \\
0.1065=11 \%\end{array}$ & $2.4793=2$ & $19 \%$ \\
\hline 16 & $8.5615=9$ & & $2.0082=2$ & $19 \%$ \\
\hline 17 & $6.9348=7$ & & $1.6267=2$ & $19 \%$ \\
\hline 18 & $5.6172=6$ & & $1.3176=1$ & $19 \%$ \\
\hline 19 & $4.5499=5$ & & $1.0673=1$ & $19 \%$ \\
\hline 20 & $\begin{array}{l}3.6854=4 \\
\text { Total predicted to } \\
\text { recidivate within } \\
20 \text { years }= \\
1061.9132= \\
1062\end{array}$ & $\begin{array}{c}1061.9132 / 9691= \\
11 \%\end{array}$ & $0.8645=1$ & $19 \%$ \\
\hline
\end{tabular}


should be seen as predicting the percentage of those released sex offenders who would be arrested for a new sex crime within their lifetime.

\section{Extrapolated Recidivism Rates for Child Molesters}

I will now repeat the above process to predict recidivism rates for child molesters twenty years after release from prison. Just as with sex offenders, the first step required coming up with an estimated decrease per year. To do this, I calculated the percentage drop in child molesters who were rearrested for a new sex crime against a child between year I and year 2, yielding 23 percent $(94-72=22 ; 22 / 94=0.2340=23$ percent $)$. I then calculated the drop between year 2 and year 3 , yielding 26 percent $(72-53=$ 19; $19 / 72=0.2639=26$ percent). Again, I acknowledge that this is not a perfect method, and it assumes that recidivism will continue in a similar downward trend, which we have no way of really knowing.

To calculate the predicted drop between year 3 and year 4 and further through year 20 , I averaged the decreases between year $I$ and year 2 and between year 2 and year 3 , yielding 25 percent $(0.234+0.2639=0.4974$; $0.4974 / 2=0.2490=25$ percent). It should be noted once again that 25 percent is a conservative estimate because the data we have shows that the arrest rate was dropping faster. These calculations also show that Hanson's finding, that sex offender recidivism dropped by so percent over five years, is not borne out by the DOJ data. Child offender recidivism dropped by 49 percent in only the first three years.

I then used 25 percent to calculate the number of child molesters I expected to recidivate through year 20 . Specifically, I multiplied the total number who recidivated in year 3 (53) by 0.25 to get the difference in the number I expected would recidivate in year 4 ( 13.25$)$. I then subtracted that number from year 3 to get the estimated number who would recidivate in year 4 and rounded it up $(53-13.25=39.75=40)$. I then repeated this process for each of the subsequent years by starting with the estimated number who would recidivate for year $X$, multiplying that number by 0.25 , then subtracting that number from year $X$ to get the number I expected would recidivate in year $\mathrm{X}+\mathrm{I}$. Table 20 shows the results.

The above analysis shows that after year 15 , recidivism remained almost unchanged. The numbers drop so much that, even extrapolating 100 years into the future, recidivism is not expected to exceed 9 percent. Thus this table should be seen as predicting the percentage of those released child molesters who would be arrested for a new sex crime within their lifetime. 
Table 20. Extrapolated child molester recidivism rates based on DOJ data extrapolated for years 4-20 after release from prison (recidivism is defined as rearrest for a new sex crime against a child)

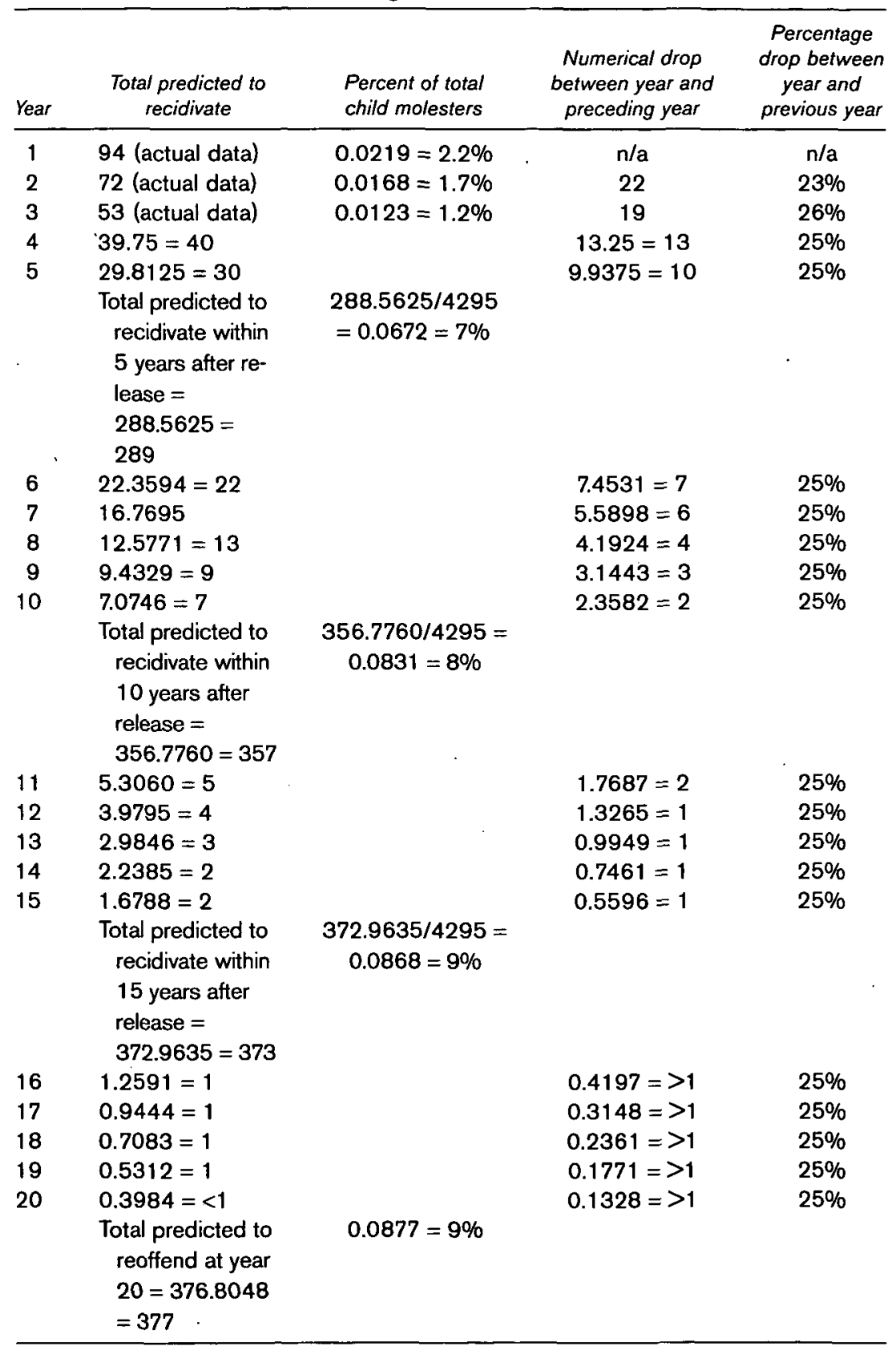

